\title{
A genetically encoded toolkit of functionalized nanobodies against fluorescent proteins for visualizing and manipulating intracellular signalling
}

\author{
David L. Prole* and Colin W. Taylor ${ }^{*}(1)$
}

\begin{abstract}
Background: Intrabodies enable targeting of proteins in live cells, but generating specific intrabodies against the thousands of proteins in a proteome poses a challenge. We leverage the widespread availability of fluorescently labelled proteins to visualize and manipulate intracellular signalling pathways in live cells by using nanobodies targeting fluorescent protein tags.
\end{abstract}

Results: We generated a toolkit of plasmids encoding nanobodies against red and green fluorescent proteins (RFP and GFP variants), fused to functional modules. These include fluorescent sensors for visualization of $\mathrm{Ca}^{2+}, \mathrm{H}^{+}$and ATP/ADP dynamics; oligomerising or heterodimerising modules that allow recruitment or sequestration of proteins and identification of membrane contact sites between organelles; SNAP tags that allow labelling with fluorescent dyes and targeted chromophore-assisted light inactivation; and nanobodies targeted to lumenal sub-compartments of the secretory pathway. We also developed two methods for crosslinking tagged proteins: a dimeric nanobody, and RFP-targeting and GFP-targeting nanobodies fused to complementary hetero-dimerizing domains. We show various applications of the toolkit and demonstrate, for example, that $\mathrm{IP}_{3}$ receptors deliver $\mathrm{Ca}^{2+}$ to the outer membrane of only a subset of mitochondria and that only one or two sites on a mitochondrion form membrane contacts with the plasma membrane.

Conclusions: This toolkit greatly expands the utility of intrabodies and will enable a range of approaches for studying and manipulating cell signalling in live cells.

Keywords: Cell signalling, Endoplasmic reticulum, Fluorescence microscopy, Fluorescent protein, GFP, Intrabody, Membrane contact site, Mitochondria, Nanobody, RFP

\section{Background}

Visualizing the location of specific proteins within cells and manipulating their function is crucial for understanding cell biology. Antibodies can define protein locations in fixed and permeabilized cells, but antibodies are large protein complexes that are difficult to introduce into live cells [1]. This limits their ability to interrogate the dynamics or affect the function of proteins in live cells. Small protein-based binders, including nanobodies derived from the variable region of the heavy chains

\footnotetext{
* Correspondence: dp350@cam.ac.uk; cwt1000@cam.ac.uk Department of Pharmacology, University of Cambridge, Tennis Court Road, Cambridge CB2 1PD, UK
}

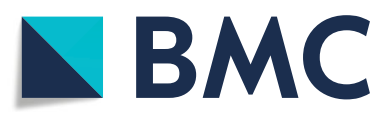

(c) The Author(s). 2019 Open Access This article is distributed under the terms of the Creative Commons Attribution 4.0 International License (http://creativecommons.org/licenses/by/4.0/), which permits unrestricted use, distribution, and reproduction in any medium, provided you give appropriate credit to the original author(s) and the source, provide a link to the Creative Commons license, and indicate if changes were made. The Creative Commons Public Domain Dedication waiver (http://creativecommons.org/publicdomain/zero/1.0/) applies to the data made available in this article, unless otherwise stated.
$\left(\mathrm{V}_{\mathrm{HH}}\right)$ of camelid antibodies, offer a promising alternative [2]. Nanobodies can be encoded by plasmids and expressed in live cells. However, generating nanobodies against thousands of protein variants is daunting, and even for single targets, it can be time-consuming, costly and not always successful. A solution to this bottleneck is provided by fluorescently tagged proteins, which are widely used in cell biology [3, 4] after heterologous expression of proteins or gene editing of endogenous proteins [5-7]. The most common application of fluorescent protein (FP) tags is to visualize protein locations, but they have additional potential as generic affinity tags 
to manipulate and visualize protein functions in live cells. These opportunities are under-developed.

Green fluorescent protein (GFP) has undergone numerous cycles of optimization as a reporter and nonperturbing tag $[3,8]$. Most GFP-tagged proteins therefore retain their endogenous localization and function [9]. Large libraries of plasmids encoding GFP-tagged proteins are now available [10]. Proteome-scale expression of GFP-tagged proteins or genome-scale tagging of gene products with GFP has been reported for Drosophila [11], fungi [12-14], plants [15, 16] and bacteria [17].

Proteins tagged with red fluorescent proteins (RFPs) such as DsRed, mRFP and mCherry $(\mathrm{mCh})$ are also popular. Extensive optimization has made them attractive tags $[3,18]$, and libraries of RFP-tagged proteins have been developed in mouse stem cells [19] and yeast [14].

Nanobodies that bind to RFP [20, 21] or GFP [21, 22] are most commonly used in their purified forms for immunoprecipitation and immunocytochemistry. However, they also offer a generic means of targeting in live cells the huge variety of available tagged proteins and the many emerging examples of endogenous proteins tagged with FPs by gene editing. GFP-targeting nanobodies have been used for applications such as targeted proteasomal degradation [23, 24] and relocation of proteins in cells [25], but these and other applications are less developed for RFP-targeting nanobodies.

Here we develop a plasmid-encoded toolkit of nanobodies that bind common FP tags, including RFPs, CFP, GFP and YFP, fused to functional modules for visualization and manipulation of cell signalling (Fig. 1). We fused the nanobodies to a variety of functional modules: fluorescent sensors for $\mathrm{Ca}^{2+}, \mathrm{H}^{+}$and ATP/ ADP; optimized SNAP tags for labelling with bright and photostable dyes [26]; and hetero-dimerizing partners that allow inducible recruitment or sequestration of proteins and visualization of membrane contact sites (MCS) between organelles. We developed two methods to allow crosslinking of RFP-tagged and GFP-tagged proteins: a dimeric nanobody, and co-expression of RFP-targeting and GFP-targeting nanobodies fused to complementary hetero-dimerizing domains. We also describe functionalized nanobodies directed to lumenal sub-compartments of the secretory pathway. We demonstrate the utility of nanobody fusions by visualizing local $\mathrm{Ca}^{2+}$ dynamics at the surface of mitochondria, by manipulating the locations of proteins and organelles within cells, by characterizing MCS between mitochondria and the plasma membrane (PM) and by targeting lumenal $\mathrm{Ca}^{2+}$ sensors to a sub-compartment of the endoplasmic reticulum (ER).

This versatile toolkit of genetically encoded, functionalized nanobodies greatly expands the utility of RFP- and GFP-targeting nanobodies. It will provide a valuable resource for studying protein function and cell signalling in live cells. We illustrate some applications and demonstrate, for example, that $\mathrm{IP}_{3}$ receptors deliver $\mathrm{Ca}^{2+}$ to the outer membrane of only some mitochondria and that MCS between mitochondria and the plasma membrane occur at only one or two sites on each mitochondrion.

\section{Results}

Targeting RFP and GFP variants with genetically encoded nanobody fusions in live cells

The RFP nanobody (RNb) and GFP nanobody (GNb) used are the previously described llama variants LaM4 and LaG16, respectively [21]. They were chosen for their favourable combinations of high affinity $\left(K_{d}\right.$ values of $0.18 \mathrm{nM}$ and $0.69 \mathrm{nM}$, respectively) and the ability to bind a variety of RFP or GFP variants [21]. The latter attribute maximizes their potential for targeting a wide variety of FPs $[3,4]$. LaM4 binds both $\mathrm{mCh}$ and DsRed variants, but not GFPs [21]. In addition to binding GFP, LaG16 binds cyan, blue and yellow FPs (CFP, BFP and YFP), but not RFPs [21]. In contrast, the widely used VhhGFP4 nanobody binds GFP, but not CFP [22].

In HeLa cells with organelles (ER, mitochondria, nucleus and lysosomes) labelled with $\mathrm{mCh}$ or mRFP markers, expression of RNb-GFP (Fig. 2a) specifically identified the labelled organelle (Fig. 2b). Similar results were obtained with GNb-mCh (Fig. 2c) and organelles (ER, mitochondria and nucleus) labelled with GFP or mTurquoise (Fig. 2d). These results demonstrate that plasmid-encoded $\mathrm{RNb}$ and GNb allow specific labelling of a variety of RFP and GFP variants in live cells.

\section{Targeting sensors to RFP and GFP}

The effects of intracellular messengers such as $\mathrm{Ca}^{2+}$ [27], $\mathrm{H}^{+}$[28] and ATP/ADP [29] can be highly localized within cells. To enable visualization of these intracellular messengers in microdomains around RFP-tagged and GFP-tagged proteins, we fused $\mathrm{RNb}$ and $\mathrm{GNb}$ to fluorescent sensors for $\mathrm{Ca}^{2+}[30], \mathrm{H}^{+}[31,32]$ or ATP/ADP [33].

$\mathrm{RNb}$ was fused to the green fluorescent $\mathrm{Ca}^{2+}$ sensor G-GECO1.2 (Fig. 3), and GNb was fused to the red fluorescent $\mathrm{Ca}^{2+}$ sensors, R-GECO1.2 or LAR-GECO1.2 [30] (Fig. 4). The affinities of these sensors for $\mathrm{Ca}^{2+}\left(\mathrm{K}_{\mathrm{D}}^{\mathrm{Ca}}\right.$ of $1.2 \mu \mathrm{M}$ for G-GECO1.2 and R-GECO1.2, and $10 \mu \mathrm{M}$ for LAR-GECO1.2) are low relative to global changes in the cytosolic free $\mathrm{Ca}^{2+}$ concentration $\left(\left[\mathrm{Ca}^{2+}\right]_{\mathrm{c}}\right)$ after receptor stimulation (typically $\sim 300 \mathrm{nM}$ ) [34]. This facilitates selective detection of the large, local rises in $\left[\mathrm{Ca}^{2+}\right]$ that are important for intracellular signalling, at the contacts between active inositol 1,4,5-trisphosphate receptors $\left(\mathrm{IP}_{3} \mathrm{Rs}\right)$ and mitochondria, for example [27]. To allow targeted measurement of relatively low resting $\left[\mathrm{Ca}^{2+}\right]$ within cellular microdomains, we also fused $\mathrm{RNb}$ to the ratiometric $\mathrm{Ca}^{2+}$-sensor, GEMGECO1 $\left(\mathrm{K}_{\mathrm{D}}^{\mathrm{Ca}}=300 \mathrm{nM}\right)$ [30], to give RNb-GEMGECO1 (Additional file 1: Figure S1). 


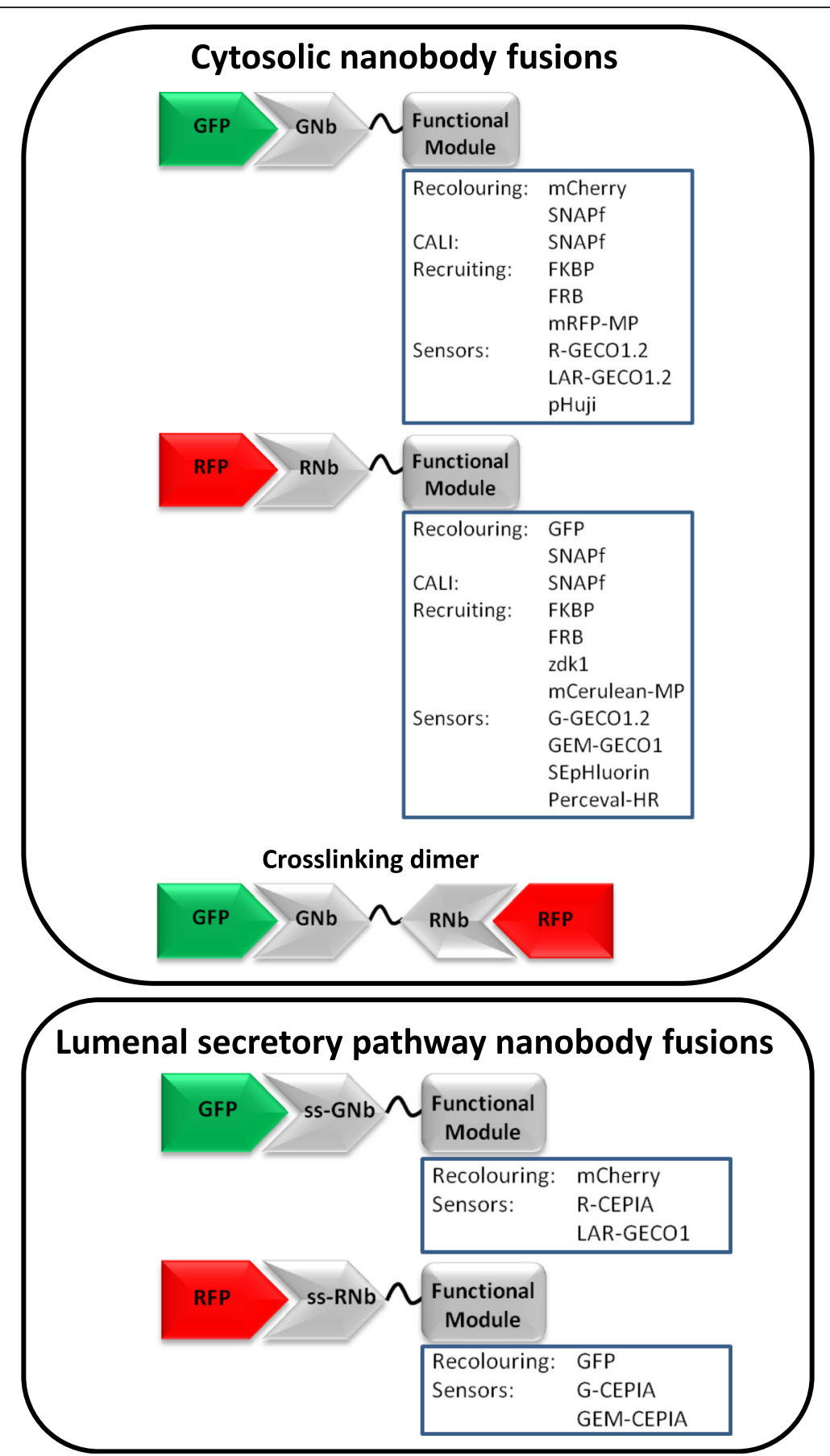

Fig. 1 Nanobody fusions for visualizing and manipulating intracellular signalling. Plasmids were generated that encode nanobodies specific for GFP variants (GNb) or RFP variants (RNb), fused to functional modules. Nanobody fusions with an N-terminal signal sequence to target them to the secretory pathway are also shown (ssGNb and ssRNb)

In HeLa cells expressing TOM20-mCh or TOM20GFP to identify the outer mitochondrial membrane (OMM), the $\mathrm{RNb}-\mathrm{Ca}^{2+}$ sensors (Fig. 3 and Additional file 1: Figure S1) and $\mathrm{GNb}-\mathrm{Ca}^{2+}$ sensors (Fig. 4) were targeted to the OMM. Both families of targeted sensor reported an increase in $\left[\mathrm{Ca}^{2+}\right]$ after treatment with the $\mathrm{Ca}^{2+}$ ionophore, ionomycin (Figs. 3 and 4 and Additional file 1: Figure S1). This confirms the ability of the sensors to report $\left[\mathrm{Ca}^{2+}\right]$ changes when targeted to the OMM microdomain.

In some cells, the targeted $\mathrm{Nb}-\mathrm{Ca}^{2+}$ sensors revealed local changes in $\left[\mathrm{Ca}^{2+}\right]_{\mathrm{c}}$ after receptor stimulation with histamine, which stimulates $\mathrm{IP}_{3}$ formation and $\mathrm{Ca}^{2+}$ 

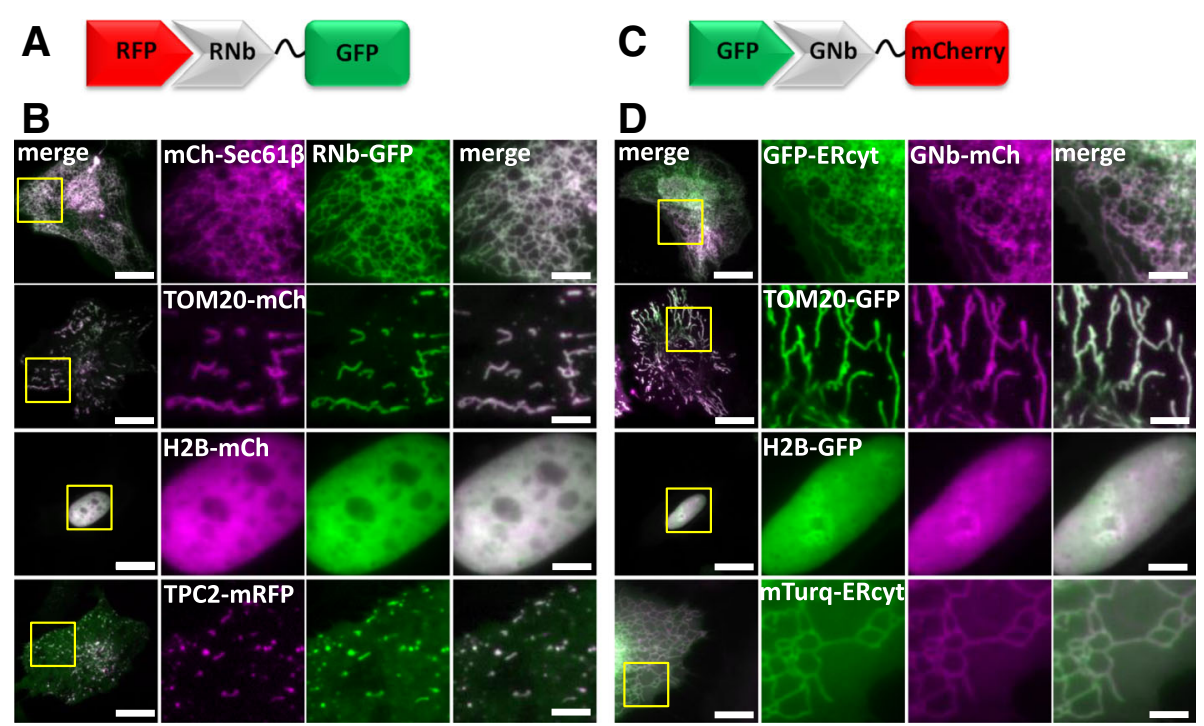

Fig. $2 \mathrm{RNb}$ and GNb fusion proteins bind to their respective tagged proteins in live cells. a Schematic of the RNb-GFP fusion binding to RFP. b HeLa cells expressing RNb-GFP with RFP-tagged markers for the ER surface (mCh-Sec61ß), the mitochondrial surface (TOM20-mCh), the nucleus (H2B-mCh), or the surface of lysosomes (TPC2-mRFP). Cells were imaged in HBS using epifluorescence microscopy (cells expressing H2B-mCh) or TIRFM (other cells). Yellow boxes indicate regions enlarged in the subsequent panels. Colocalization values (Pearson's coefficient, $r$ ) were $\mathrm{mCh}$-Sec61 $\beta(r=0.93 \pm$ $0.09, n=10$ cells), TOM20-mCh ( $r=0.94 \pm 0.09, n=10$ cells), H2B-mCh ( $r=0.97 \pm 0.06, n=10$ cells), and TPC2-mRFP ( $r=0.78 \pm 0.09, n=5$ cells). c Schematic of the GNb-mCh fusion binding to GFP. $\mathbf{d}$ HeLa cells co-expressing GNb-mCh with GFP-tagged markers for the ER surface (GFP-ERcyt), the mitochondrial surface (TOM20-GFP), and the nucleus (H2B-GFP), or an mTurquoise2-tagged ER surface marker (mTurq-ERcyt). Cells were imaged using epifluorescence microscopy (cells expressing H2B-GFP) or TIRFM (other cells). Yellow boxes indicate regions enlarged in the subsequent panels. Colocalization values were GFP-ERcyt $(r=0.92 \pm 0.08, n=8$ cells), TOM20-GFP $(r=0.87 \pm 0.05, n=7$ cells), H2B-GFP ( $r=0.94 \pm 0.07, n=6$ cells), and mTurq-ERcyt $(r=0.97 \pm 0.03, n=7$ cells). Scale bars $10 \mu \mathrm{m}$ (main images) or $2.5 \mu \mathrm{m}$ (enlargements)

release from the ER in HeLa cells [34]. Imperfect targeting of the RNb-GGECO1.2 to the OMM allowed $\mathrm{Ca}^{2+}$ signals at the surface of individual mitochondria to be distinguished from those in nearby cytosol in some cells (Fig. 3d-f and Additional file 2: Video 1). In the example shown, RNb-GGECO1.2 at both the OMM and nearby cytosol responded to the large, global increases in $\left[\mathrm{Ca}^{2+}\right]$ evoked by ionomycin. However, cytosolic RNb-GGECO1.2 did not respond to histamine, while the sensor at the OMM responded with repetitive spiking (Fig. $3 \mathrm{~d}-\mathrm{f}$ and Additional file 2: Video 1). The GNb-LARGECO1.2 sensor, which has the lowest affinity for $\mathrm{Ca}^{2+}$ of the sensors used, revealed changes in $\left[\mathrm{Ca}^{2+}\right]_{\mathrm{c}}$ at the surface of some mitochondria, but not others in the same cell (Fig. 4d-f, Fig. 4h and Additional file 3: Video 2). In the example shown, GNb-LARGECO1.2 at the OMM in all mitochondria within the cell responded to the large, global increases in $\left[\mathrm{Ca}^{2+}\right]$ evoked by ionomycin. However, in response to histamine, mitochondria in the perinuclear region responded, but not those in peripheral regions (Fig. 4d-f, Fig. 4h and Additional file 3: Video 2). $\mathrm{Ca}^{2+}$ uptake by mitochondria affects many cellular responses, including mitochondrial metabolism, ATP production and apoptosis [35]; and $\mathrm{Ca}^{2+}$ at the cytosolic face of the OMM regulates mitochondrial motility [36]. The subcellular heterogeneity of mitochondrial exposure to increased $\left[\mathrm{Ca}^{2+}\right]$ suggests that these responses may be very localized in cells.

These observations align with previous reports showing that $\mathrm{Ca}^{2+}$-mobilizing receptors evoke both oscillatory $\left[\mathrm{Ca}^{2+}\right]$ changes within the mitochondrial matrix [37], and large local increases in $\left[\mathrm{Ca}^{2+}\right]$ at the cytosolic face of the OMM [38]. Our results establish that nanobody- $\mathrm{Ca}^{2+}$-sensor fusions are functional and appropriately targeted and can be used to detect physiological changes in $\left[\mathrm{Ca}^{2+}\right]$ within cellular microdomains such as the OMM.

For targeted measurements of intracellular $\mathrm{pH}, \mathrm{RNb}$ was fused to the green fluorescent $\mathrm{pH}$ sensor super-ecliptic pHluorin (SEpHluorin) [31], and GNb was fused to the red fluorescent $\mathrm{pH}$ sensor pHuji [32]. Both $\mathrm{Nb}-\mathrm{pH}$ sensors were targeted to the OMM by the appropriate fluorescent tags, where they responded to changes in intracellular $\mathrm{pH}$ imposed by altering extracellular $\mathrm{pH}$ in the presence of the $\mathrm{H}^{+} / \mathrm{K}^{+}$ionophore nigericin (Fig. 5).

For targeted measurements of ATP/ADP, RNb was fused to the excitation-ratiometric ATP/ADP sensor Perceval-HR [33]. RNb-Perceval-HR was targeted to the surface of mitochondria and responded to inhibition of glycolysis and oxidative phosphorylation (Fig. 6).

The results demonstrate that nanobodies can be used to direct sensors for $\mathrm{Ca}^{2+}, \mathrm{H}^{+}$or ATP/ADP to 


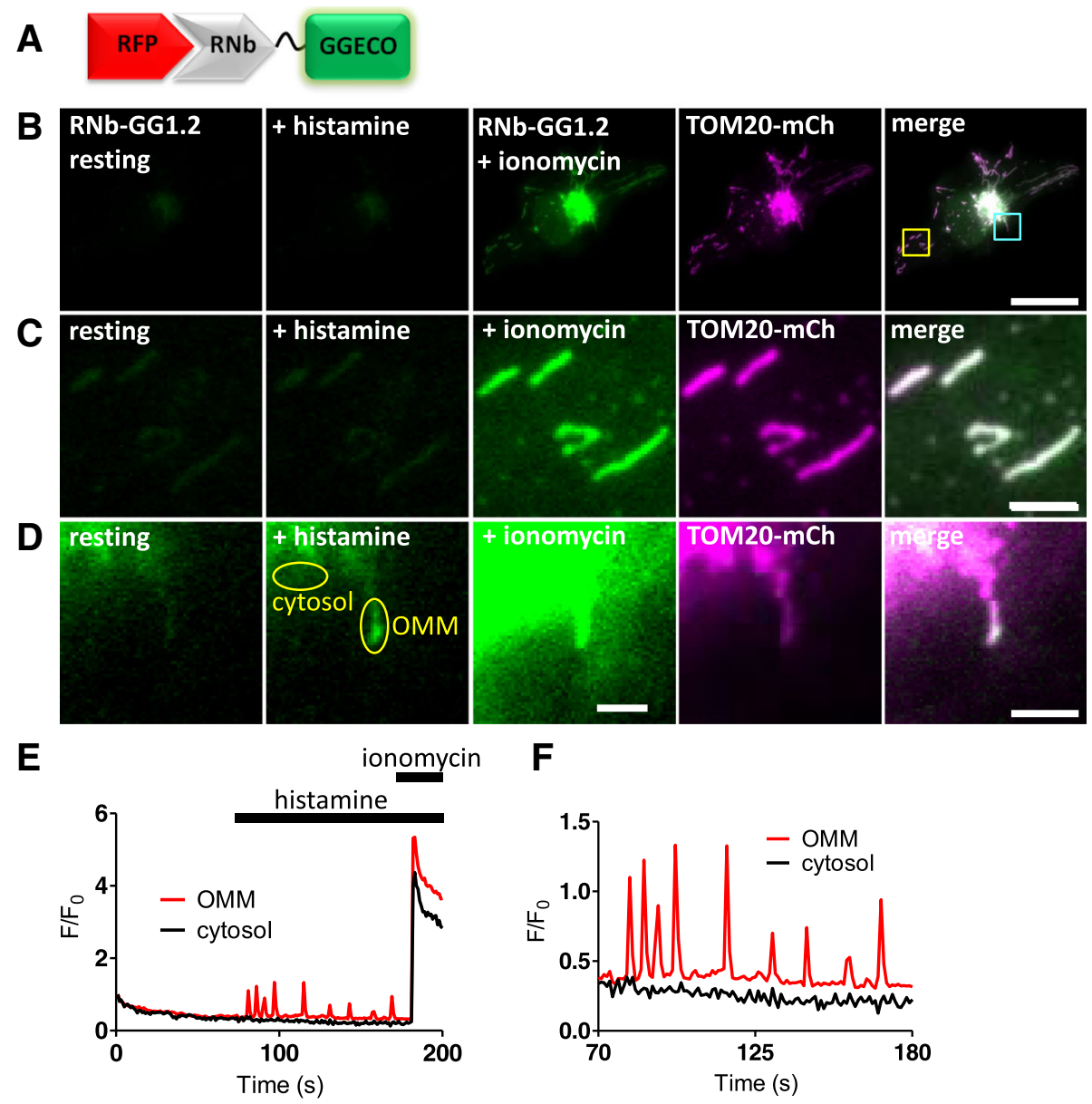

Fig. 3 Targeting RNb-Ca ${ }^{2+}$ sensors to RFP-tagged proteins. a Schematic of RNb-GGECO fusion binding to RFP. b-d HeLa cells expressing RNbGGECO1.2 and TOM20-mCh, before and after addition of histamine (100 $\mu \mathrm{M})$ and then ionomycin $(5 \mu \mathrm{M})$. Cells were imaged in HBS using TIRFM The TOM20-mCh image is shown after the histamine and ionomycin additions. The merged images are shown using images of RNb-GGECO1.2 after ionomycin $(\mathbf{b}, \mathbf{c})$ or histamine (d). The yellow and cyan-boxed regions in panel $\mathbf{b}$ are shown enlarged in panels $\mathbf{c}$ and $\mathbf{d}$, respectively. Scale bars are $10 \mu \mathrm{m}(\mathbf{b})$ or $1.25 \mu \mathrm{m}(\mathbf{c}, \mathbf{d})$. e Timecourse of the effects of histamine $(100 \mu \mathrm{M})$ and ionomycin $(5 \mu \mathrm{M})$ on the fluorescence of RNb-GGECO1.2 (F/Fo, where $F$ and $F_{0}$ are fluorescence recorded at $t$ and $t=0$ ). The traces are from regions coinciding with a single mitochondrion or cytosol (regions identified in panel d), indicating changes in $\left[\mathrm{Ca}^{2+}\right]$ at the OMM. f Enlarged region (70-180 s) of the graph is shown in e. Results are representative of cells from 13 independent experiments

specific subcellular compartments tagged with variants of RFP or GFP.

\section{Targeting SNAPf tags to RFP and GFP in live cells}

SNAP, and related tags, are versatile because a range of SNAP substrates, including some that are membranepermeant, can be used to attach different fluorophores or cargoes to the tag [39]. Purified GFP-targeting nanobodies fused to a SNAP-tag have been used to label fixed cells for optically demanding applications [40]. We extended this strategy to live cells using $\mathrm{RNb}$ and $\mathrm{GNb}$ fused to the optimized SNAPf tag [41] (Fig. 7a, b). In cells expressing the mitochondrial marker TOM20-mCh, RNb-SNAPf enabled labelling of mitochondria with the cell-permeable substrate SNAP-Cell 647-SiR and imaging at far-red wavelengths (Fig. 7c). In cells expressing lysosomal LAMP1-mCh and RNb-SNAPf, SNAP-Cell 647-SiR instead labelled lysosomes (Fig. 7d), demonstrating that SNAP-Cell 647-SiR specifically labelled the organelles targeted by RNb-SNAPf. Similar targeting of SNAP-Cell 647-SiR to mitochondria (Fig. 7e) and lysosomes (Fig. 7f) was achieved by GNb-SNAPf co-expressed with the appropriate GFP-tagged organelle markers.

Chromophore-assisted light inactivation (CALI) can inactivate proteins or organelles by exciting fluorophores attached to them that locally generate damaging reactive superoxide. Historically, antibodies were used to direct a photosensitizer to its target, but the fusion of fluorescent proteins or SNAP-tags to proteins of interest is now widely used [42]. RNb-SNAPf and GNb-SNAPf make 


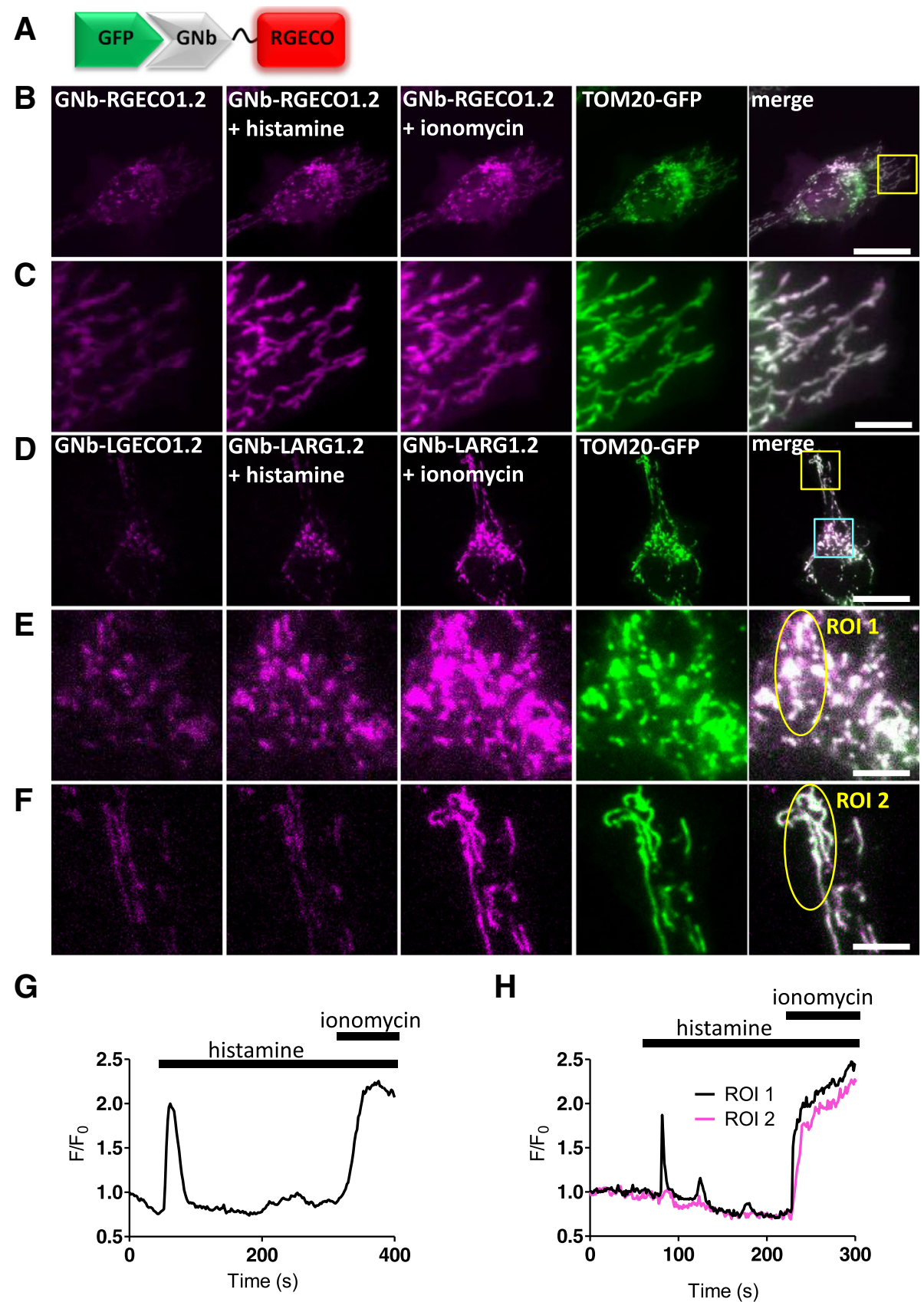

Fig. 4 Targeted GNb-Ca ${ }^{2+}$ sensors detect changes in $\left[\mathrm{Ca}^{2+}\right]$ at the surface of mitochondria. a Schematic of GNb-RGECO fusion binding to GFP. b, c Representative HeLa cells co-expressing TOM20-GFP and GNb-RGECO1.2 imaged in HBS using TIRFM before and after addition of histamine $(100 \mu \mathrm{M})$ and then ionomycin $(5 \mu \mathrm{M})$. The TOM20-GFP images are shown after the histamine and ionomycin additions. Histamine and ionomycin evoked changes in fluorescence of GNb-RGECO1.2 at the OMM. The yellow boxed region in panel B is shown enlarged in panel $\mathbf{c}$. $\mathbf{d}$-f $\mathbf{f}$ Similar analyses of HeLa cells co-expressing TOM20-GFP and GNb-LAR-GECO1.2 (GNb-LARG1.2). Histamine (100 $\mu \mathrm{M})$ evoked changes in fluorescence of GNb-LARG1.2 at the OMM of mitochondria in the perinuclear region (region of interest 1 (ROI 1) in $\mathbf{e}$ ), but not in a peripheral region (ROI 2 in $\mathbf{f}$ ). All mitochondria responded to ionomycin $(5 \mu \mathrm{M})$, indicating that histamine evoked local changes in $\left[\mathrm{Ca}^{2+}\right]$ at the OMM. The cyan and yellow boxed regions in $\mathbf{d}$ are shown enlarged in e and $\mathbf{f}$, respectively. Scale bars $10 \mu \mathrm{m}(\mathbf{b}, \mathbf{d})$ or $2.5 \mu \mathrm{m}$ (c, e and $\mathbf{f}$ ). $\mathbf{g}$ Timecourse of the changes in fluorescence of GNb-RGECO1.2 at the OMM evoked by histamine and ionomycin for the entire cell shown in B. $\mathbf{h}$ Fluorescence changes recorded from ROI 1 and ROI 2 in panels $\mathbf{e}$ and $\mathbf{f}$. Results are representative of cells from 4 independent experiments 


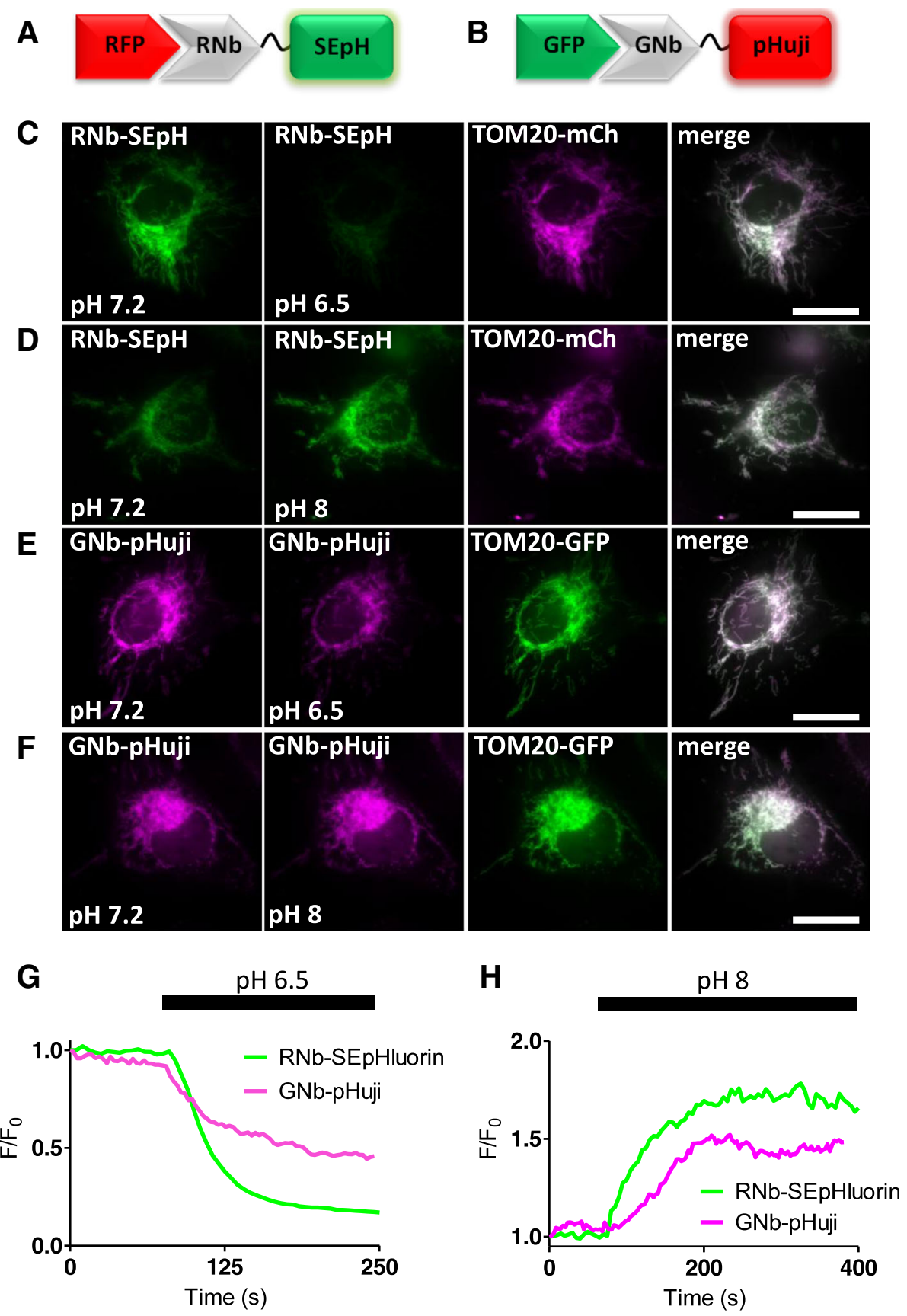

Fig. 5 Targeting $\mathrm{H}^{+}$sensors to RFP-tagged and GFP-tagged proteins. a Schematic of RNb fused to the $\mathrm{pH}$ sensor super-ecliptic pHluorin (RNbSEpH) and bound to RFP. b Schematic of GNb-pHuji binding to RFP. $\mathbf{c}$, d HeLa cells co-expressing RNb-SEpH and TOM20-mCh were imaged in modified HBS (MHBS) using epifluorescence microscopy and exposed to extracellular pH 6.5 (c) or pH 8 (d) in the presence of nigericin (10 $\mu \mathrm{M})$. Scale bars $10 \mu \mathrm{m}$. e, $\mathbf{f}$ HeLa cells co-expressing GNb-pHuji and TOM20-GFP were exposed to extracellular pH 6.5 (e) or pH 8 (f) in the presence of nigericin. Scale bars $10 \mu \mathrm{m} . \mathbf{g}$, $\mathbf{h}$ Timecourse from single cells of the fluorescence changes $\left(F / F_{0}\right)$ of mitochondrially targeted RNb-SEpH or GNbpHuji evoked by the indicated manipulations of extracellular pH. Results shown are representative of 3 independent experiments

the SNAP strategy more broadly applicable to CALI applications. We demonstrate this by targeting CALI to the outer surface of lysosomes. We anticipated that CALI in this microdomain might, amongst other effects, disrupt the motility of lysosomes, which depends on their association with molecular motors [43]. RNb-SNAPf enabled labelling of lysosomes with the CALI probe fluorescein, using the cell-permeable substrate, SNAP-Cellfluorescein (Fig. 8a, b). Exposure to blue light then immobilized the lysosomes (Fig. 8c-f and Additional file 4: Video 3), 
A
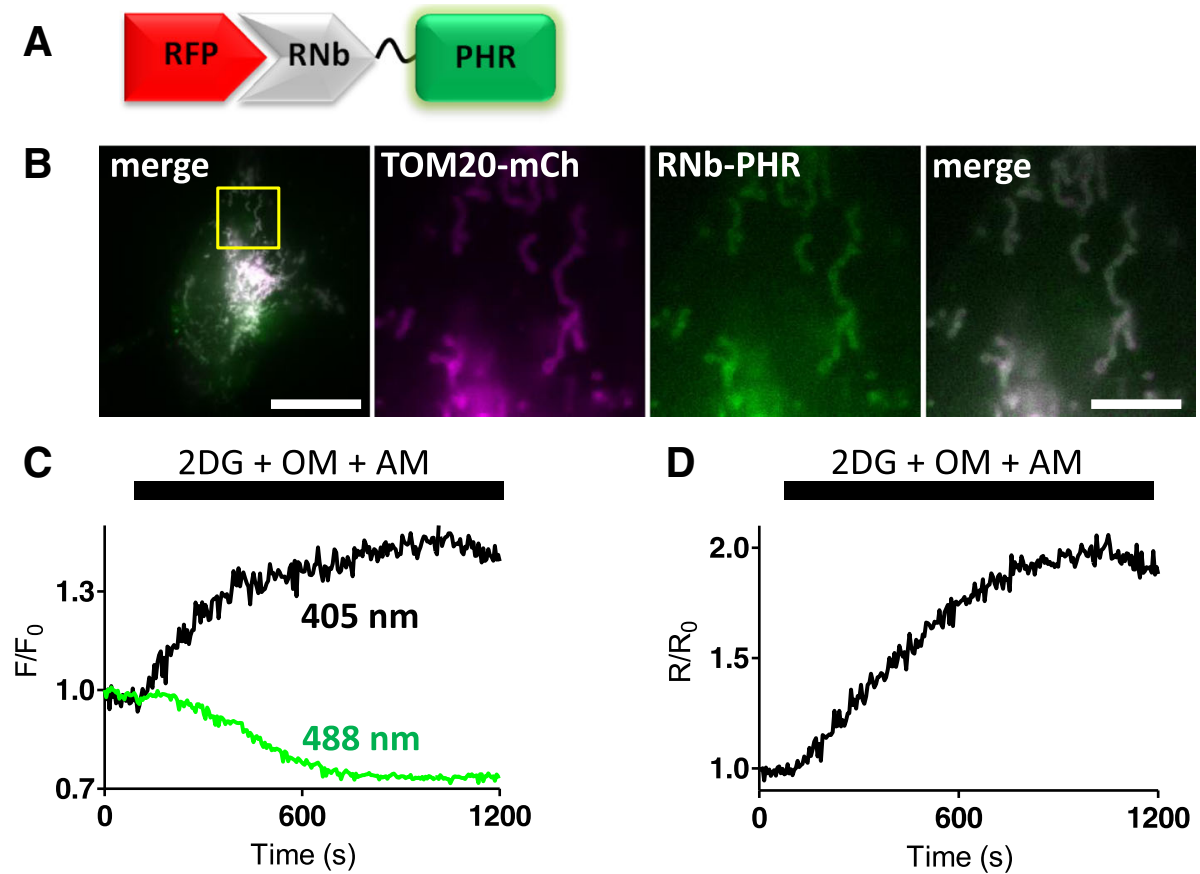

Fig. 6 Targeting an ATP/ADP sensor to RFP-tagged proteins. a Schematic of RNb-Perceval-HR fusion (RNb-PHR) bound to RFP. b HeLa cells coexpressing RNb-PHR and TOM20-mCh were imaged in HBS using epifluorescence microscopy. The yellow box indicates the region enlarged in subsequent panels. Scale bars $10 \mu \mathrm{m}$ (main image) and $2.5 \mu \mathrm{m}$ (enlarged images). c, d Changes in fluorescence for each excitation wavelength (405 and $\left.488 \mathrm{~nm}, F / F_{0}\right)(\mathbf{c})$ and their ratio $\left(R / R_{0}\right.$, where $\left.R=F_{405} / F_{488}\right)(\mathbf{d})$ of mitochondrially targeted RNb-Perceval-HR after addition of 2-deoxyglucose $(2 \mathrm{DG}, 10 \mathrm{mM})$, oligomycin $(\mathrm{OM}, 1 \mu \mathrm{M})$ and antimycin $(\mathrm{AM}, 1 \mu \mathrm{M})$. The results indicate a decrease in the ATP/ADP ratio at the OMM. Results are representative of 3 independent experiments

indicating a loss of motor-driven motility. Control experiments demonstrated that labelling cytosolic SNAPf with SNAP-Cell-fluorescein (Additional file 1: Figure S2A and S2B) had significantly less effect on lysosomal motility after exposure to blue light (Fig. 8f and Additional file 1: Figure $\mathrm{S} 2 \mathrm{C}-\mathrm{E})$. These results demonstrate that nanobody-SNAPf fusions allow targeting of fluorescent dyes in live cells, which can be used for re-colouring of tagged proteins or targeted CALI.

\section{Sequestration of proteins tagged with RFP or GFP}

The fusion of GFP nanobodies to degrons allows proteasomal degradation of GFP-tagged proteins [24], but the method is slow and cumbersome to reverse. An alternative strategy is to sequester tagged proteins so they cannot fulfill their normal functions. We used two strategies to achieve this: artificial clustering and recruitment to mitochondria.

We induced artificial clustering by fusing $\mathrm{RNb}$ or $\mathrm{GNb}$ to a multimerizing protein (MP) comprising a dodecameric fragment of $\mathrm{Ca}^{2+}$-calmodulin-dependent protein kinase II (CaMKII) [44], with an intervening fluorescent protein (mRFP or mCerulean) for visualization of the $\mathrm{Nb}$ fusion (Fig. 9a, b). RNb-mCerulean-MP caused clustering of the ER transmembrane protein $\mathrm{mCh}$ Sec61 $\beta$ (Fig. 9c, d) and caused lysosomes tagged with LAMP1-mCh to aggregate into abnormally large structures (Fig. 9e, f). GNb-mRFP-MP had the same clustering effect on lysosomes labeled with LAMP1-GFP (Fig. 9g, h) and caused clustering of GFP-tagged proteins in the cytosol (calmodulin, Fig. 9i, j), nucleus and cytosol (p53, Fig. 9k, l) or ER membranes (IP 3 R3, Fig. 9m, n).

For inducible sequestration, sometimes known as 'knocksideways' [45], we used two approaches based on heterodimerizing modules, one chemical and one optical. First, we adapted the original knocksideways method, where proteins tagged with FKBP (FK506-binding protein) are recruited by rapamycin to proteins tagged with FRB (FKBP-rapamycin-binding domain) on the OMM, and thereby sequestered. The method has hitherto relied on individual proteins of interest being tagged with FKBP [45]. RNb-FKBP and GNb-FKBP (Fig. 10a, b) extend the method to any protein tagged with RFP or GFP. For our analyses, we expressed TOM70 (an OMM protein) linked to FRB through an intermediary fluorescent protein (GFP or $\mathrm{mCh}$, to allow optical identification of the fusion protein). RNb-FKBP sequestered the ER transmembrane 


\section{A}

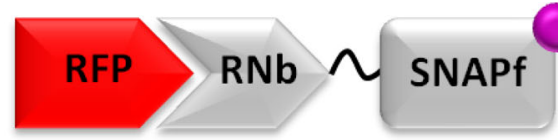

SNAPCell-647-SiR

B
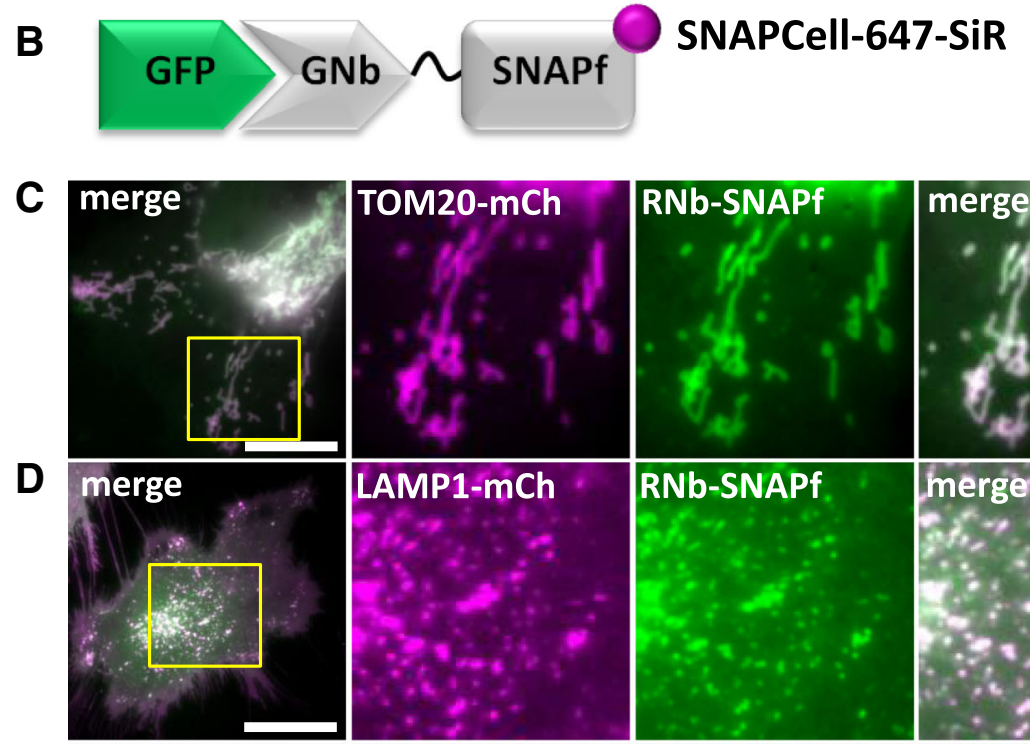

E
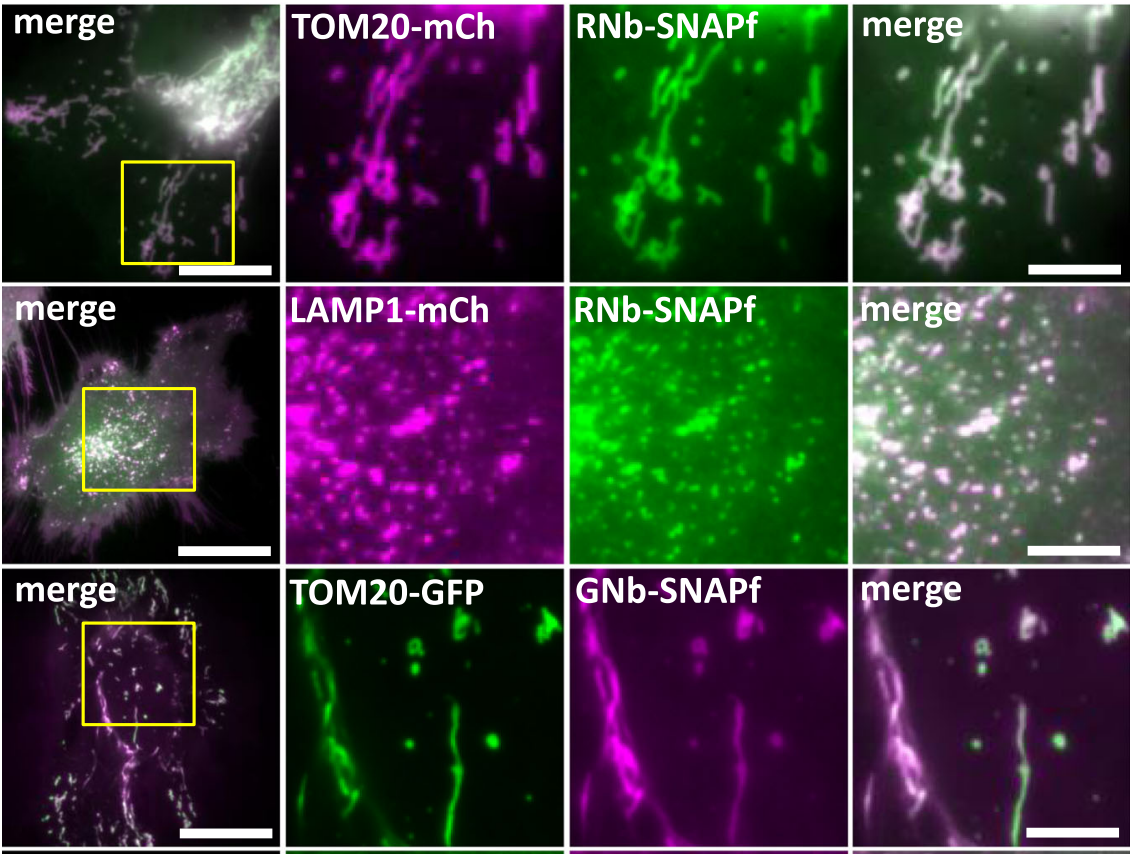

$\mathbf{F}$
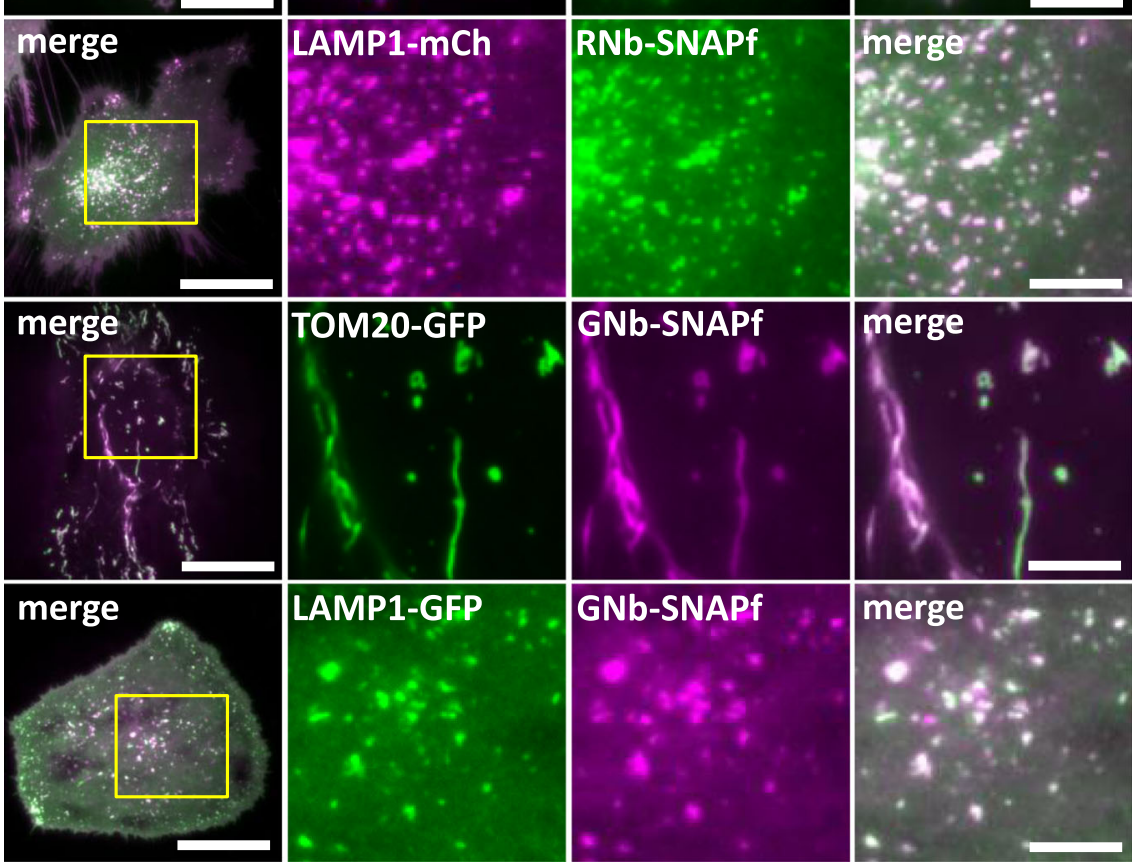

Fig. 7 Nanobody-SNAPf fusion proteins allow labelling of RFP-tagged and GFP-tagged proteins with fluorescent $\mathrm{O}^{6}$-benzylguanine derivatives in live cells. a, $\mathbf{b}$ Schematics of RNb-SNAPf fusion bound to RFP, and GNb-SNAPf fusion bound to GFP, after labelling with SNAP-Cell-647-SiR (magenta circles). $\mathbf{c}-\mathbf{f}$ HeLa cells co-expressing RNb-SNAPf and mitochondrial TOM20-mCh (c), RNb-SNAPf and lysosomal LAMP1-mCh (d), GNb-SNAPf and TOM20-GFP (e) or GNb-SNAPf and LAMP1-GFP ( $\mathbf{f}$ ) were treated with SNAP-Cell-647-SiR $\left(0.5 \mu \mathrm{M}, 30\right.$ min at $37^{\circ} \mathrm{C}$ ) and imaged using TIRFM. Scale bars $10 \mu \mathrm{m}$ (main images) or $2.5 \mu \mathrm{m}$ (enlarged images of yellow boxed regions). Colocalization values: RNb-SNAPf + TOM20-mCh ( $r=0.95 \pm 0.02, n=6$ cells); RNb-SNAPf + LAMP1-mCh $(r=0.84 \pm 0.06, n=8$ cells); GNb-SNAPf + TOM20-GFP $(r=0.78 \pm 0.09, n=10$ cells $) ;$ and GNb-SNAPf + LAMP1-GFP $(r=0.85 \pm 0.10, n=11$ cells $)$

protein $\mathrm{mCh}-\mathrm{Sec} 61 \beta$ at the OMM (TOM70-GFP-FRB) within seconds of adding rapamycin (Additional file 5: Video 4) and rapidly depleted $\mathrm{mCh}-\mathrm{Sec} 61 \beta$ from the rest of the ER (Fig. 10c-e). After addition of rapamycin, GNb-FKBP rapidly sequestered endogenous $\mathrm{IP}_{3} \mathrm{R} 1$ tagged with GFP (GFP-IP ${ }_{3}$ R1) [7] (Fig. 10f, g, and Additional file 6: Video 5) and cytosolic GFP-tagged calmodulin (Fig. 10h and Additional file 7: Video 6) at mitochondria expressing TOM70-mCh-FRB. Rapamycin caused no sequestration in the absence of the nanobody fusions (Additional file 1: Figure S3).
To make sequestration reversible and optically activated, we adapted the light-oxygen-voltage-sensing domain (LOV2)/Zdark (zdk1) system in which light induces dissociation of LOV2-zdk1 hetero-dimers [46]. Because this system is operated by blue light at intensities lower than required for imaging GFP [46], it is most suitable for use with red fluorescent tags. RNb-zdk1 (Fig. 11a) sequestered cytosolic $\mathrm{mCh}$ on the OMM in cells expressing TOM20-LOV2, and blue laser light rapidly and reversibly redistributed $\mathrm{mCh}$ to the cytosol (Fig. 11b, c). 
A

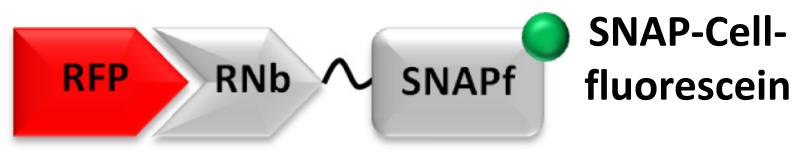

B
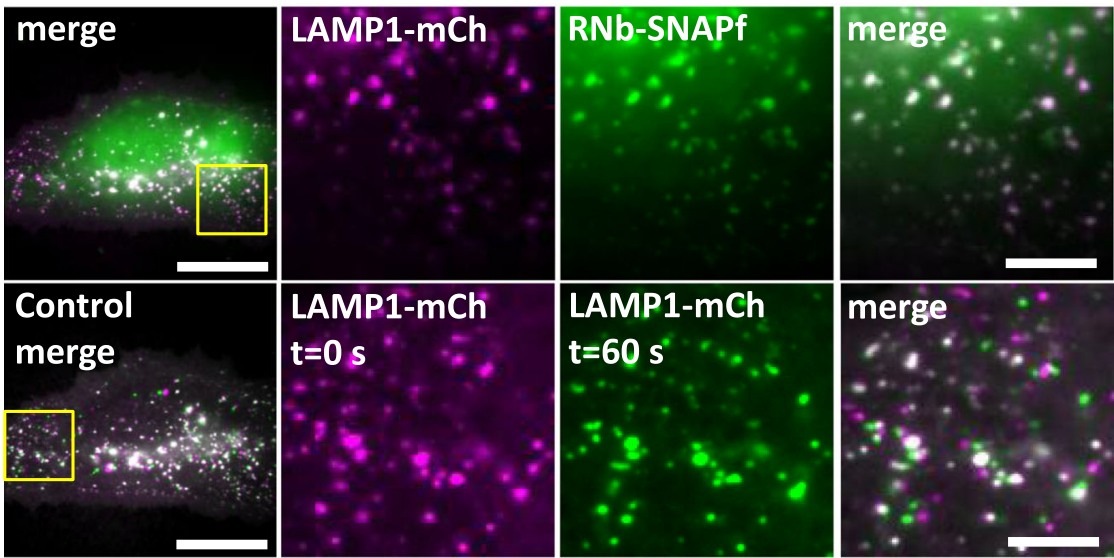

D After CALI merge
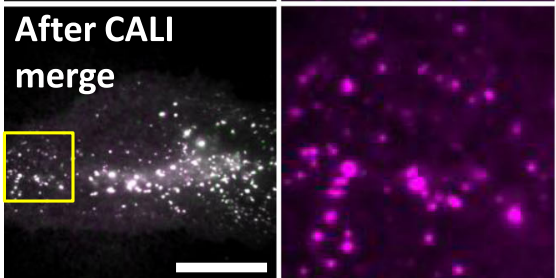

E
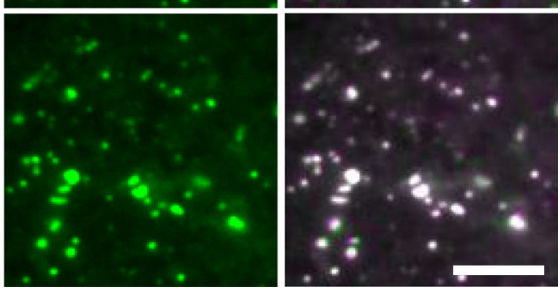

$\mathbf{F}$
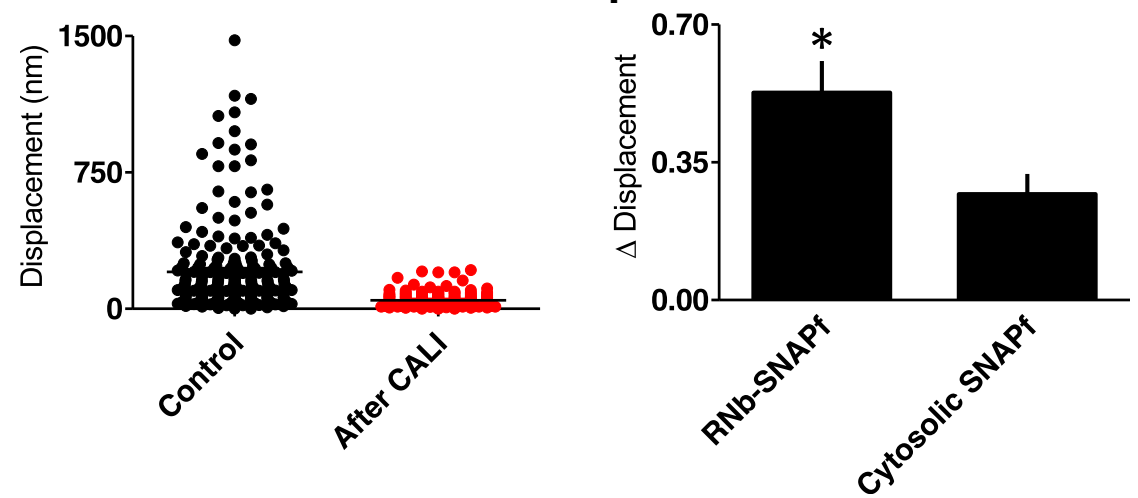

Fig. 8 Targeting CALI to lysosomes using RNb-SNAPf reduces lysosomal motility. a Schematic of RNb-SNAPf after labelling with SNAP-Cellfluorescein (green circle) and bound to RFP. $\mathbf{b}$ HeLa cells co-expressing LAMP1-mCh and RNb-SNAPf were incubated with SNAP-Cell-fluorescein $\left(0.5 \mu \mathrm{M}, 30 \mathrm{~min}, 37^{\circ} \mathrm{C}\right.$ ), which labelled lysosomes (colocalization values, $r=0.73 \pm 0.02, n=6$ cells), and imaged using TIRFM. $\mathbf{c}$, $\mathbf{d}$ Cells were then exposed to 488-nm light for $3 \mathrm{~s}$ to induce CALI. TIRFM images show a representative cell at different times before (c) and after (d) CALI, with the image at $t=0 \mathrm{~s}$ shown in magenta and the image at $t=60 \mathrm{~s}$ in green. White in the merged images from the two different times indicates immobile lysosomes, while green and magenta indicate lysosomes that moved in the interval between images. Yellow boxes show regions enlarged in subsequent images. Scale bars $10 \mu \mathrm{m}$ (main images) and $2.5 \mu \mathrm{m}$ (enlargements). For clarity, images were auto-adjusted for brightness and contrast (ImageJ) to compensate for bleaching of mCh during tracking and CALI. e Effect of CALI on the displacements of individual lysosomes, determining by particle-tracking (TrackMate), during a 60-s recording from a representative cell (images taken every $1 \mathrm{~s}$; mean values shown by bars). $\mathbf{f}$ Summary data (mean $\pm \mathrm{SEM}, n=6$ cells from 6 independent experiments) show the mean fractional decrease in displacement ( $\Delta$ displacement) due to CALI in cells expressing RNb-SNAPf or cytosolic SNAPf (see Additional file 1: Figure S2). The fractional decrease in displacement for each cell was defined as $\left(\mathrm{MD}_{\text {pre }}-\mathrm{MD}_{\text {post }}\right) / \mathrm{MD}_{\text {pre, }}$ where $M \mathrm{M}_{\text {pre }}$ and $\mathrm{MD}_{\text {post }}$ are the mean displacement of all tracked particles in $60 \mathrm{~s}$ before and after CALI. ${ }^{*} P<0.05$, unpaired Student's $t$ test 


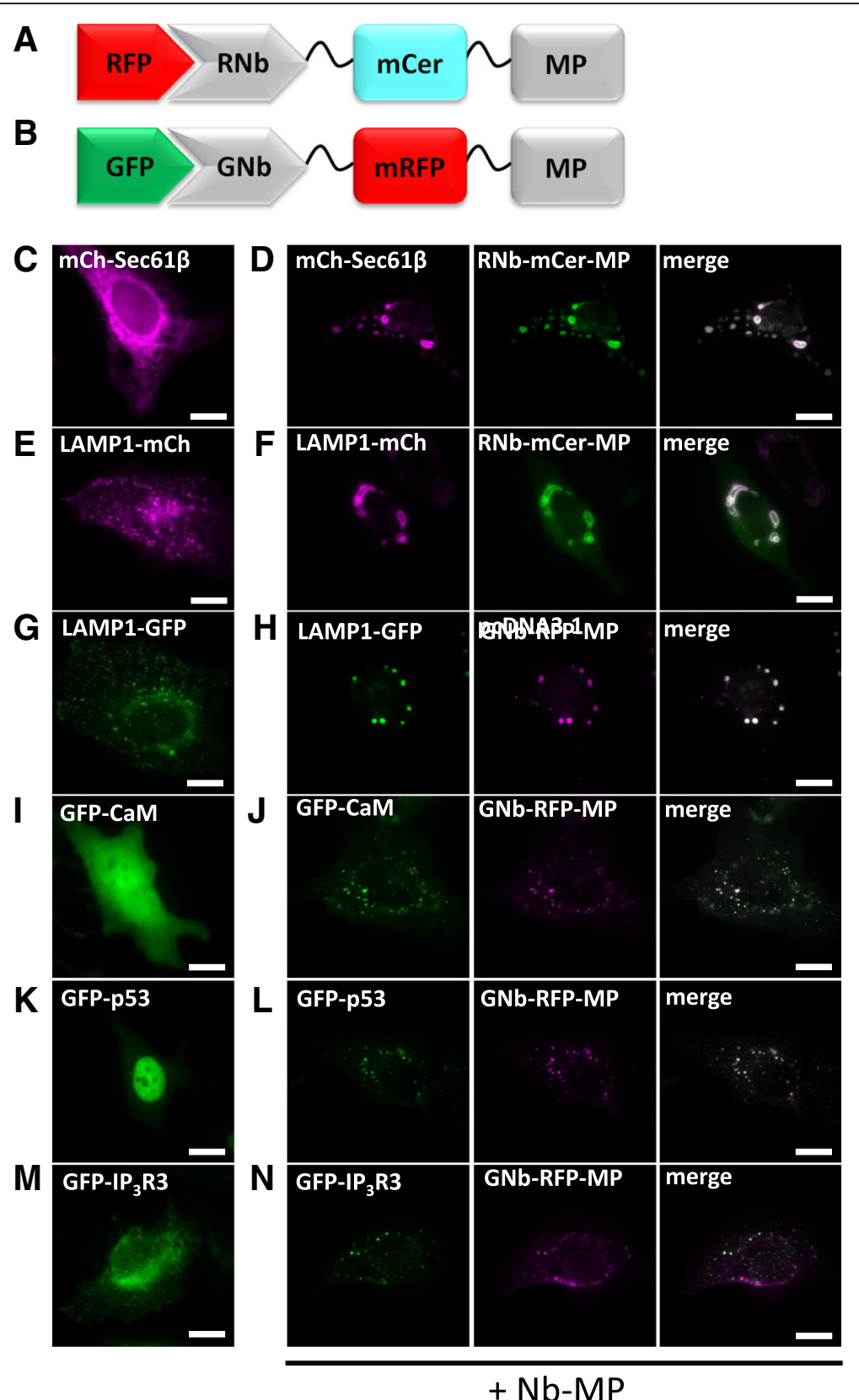

Fig. 9 Clustering of RFP-tagged and GFP-tagged proteins and organelles using RNb-mCerulean-MP and GNb-mRFP-MP. a Schematic of RNbmCerulean-MP fusion bound to RFP. $\mathbf{b}$ Schematic of GNb-mRFP-MP fusion bound to GFP. $\mathbf{c}-\mathbf{f}$ HeLa cells expressing RFP-tagged proteins in the absence $(\mathbf{c}, \mathbf{e})$ or presence $(\mathbf{d}, \mathbf{f})$ of co-expressed RNb-mCerulean-MP (RNb-mCer-MP) were imaged using epifluorescence microscopy. $\mathbf{g}-\mathbf{n}$ HeLa cells expressing GFP-tagged proteins in the absence $(\mathbf{g}, \mathbf{i}, \mathbf{k}, \mathbf{m})$ or presence $(\mathbf{h}, \mathbf{j}, \mathbf{l}, \mathbf{n})$ of co-expressed GNb-mRFP-MP were imaged using epifluorescence microscopy. Results are representative of at least 5 cells, from at least 3 independent experiments. Scale bars $10 \mu m$

Inducible recruitment of tagged proteins to membrane contact sites

The ability of Nb-FKBP fusions to recruit membrane proteins to FRB-tagged targets suggested an additional application: revealing contact sites between membrane-bound organelles. ER-mitochondrial membrane contact sites (MCS) have been much studied [47], but contacts between the PM and mitochondria, which are less extensive [48], have received less attention. In HeLa cells co-expressing the PM $\beta_{2}$-adrenoceptor tagged with $\mathrm{mCh}\left(\beta_{2} \mathrm{AR}-\mathrm{mCh}\right)$, TOM20-GFP-FRB and RNb-FKBP, rapamycin caused rapid recruitment of $\beta_{2} \mathrm{AR}-\mathrm{mCh}$ within the PM to mitochondria at discrete puncta that grew larger with time (Fig. 12a-e and Additional file 8: Video 7). Recruitment was not seen in the absence of co-expressed RNb-FKBP (Fig. 12f). Rapamycin also triggered similar punctate 

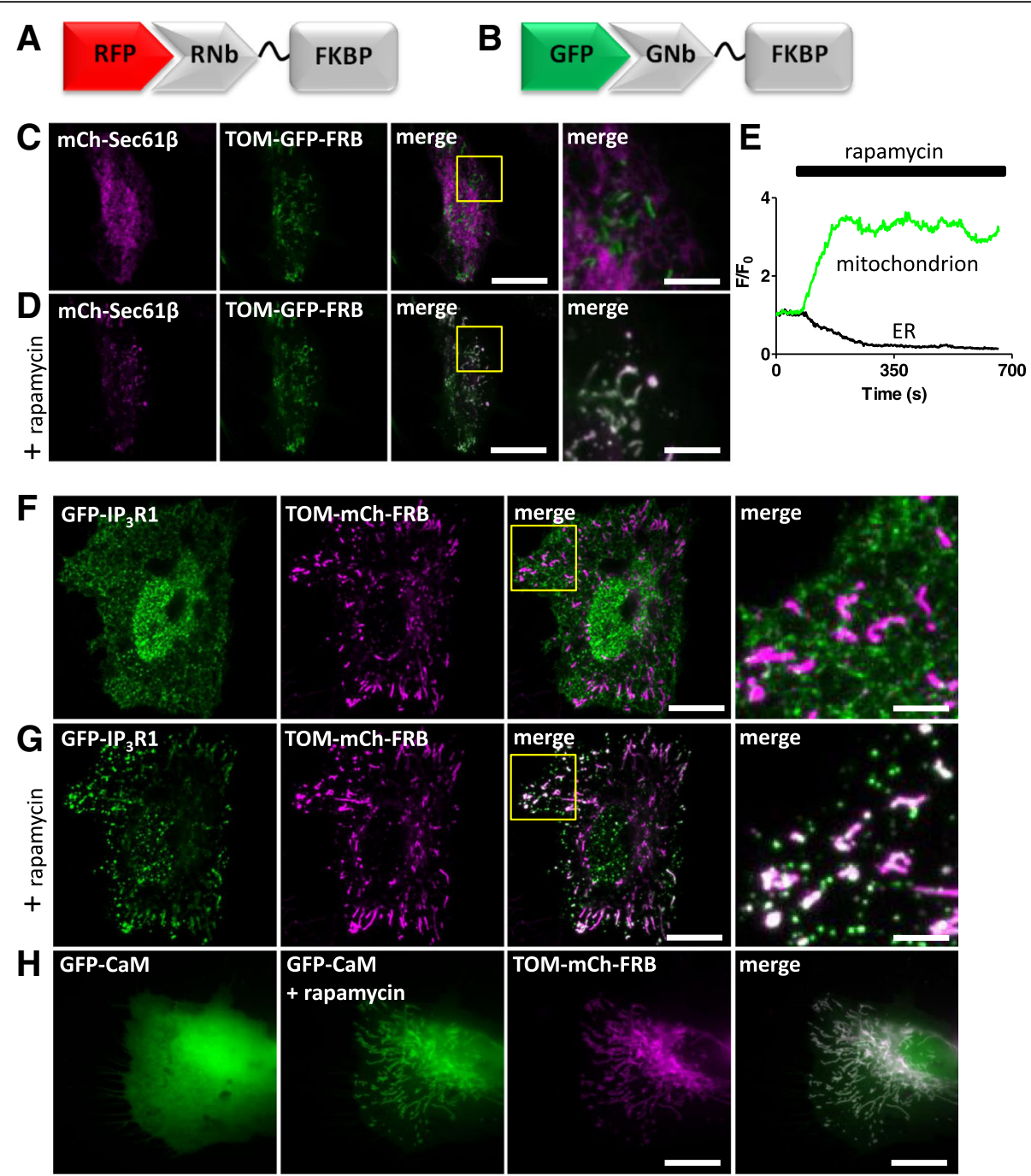

Fig. 10 RNb-FKBP inducibly recruits ER transmembrane proteins to mitochondria. a Schematic of RNb-FKBP bound to RFP. b Schematic of GNbFKBP bound to GFP. $\mathbf{c}$, $\mathbf{d}$ HeLa cells co-expressing RNb-FKBP, mitochondrial TOM70-GFP-FRB and mCh-Sec61 $\beta$ were imaged using TIRFM. A representative cell $(n=7)$ is shown before $(\mathbf{c})$ and after $(\mathbf{d})$ treatment with rapamycin (100 $\mathrm{nM}, 10 \mathrm{~min})$. The boxed region is enlarged in subsequent images. Scale bars $10 \mu \mathrm{m}$ (main images) and $2.5 \mu \mathrm{m}$ (enlargements). e Timecourse of $\mathrm{mCh}$-Sec61 $\beta$ fluorescence changes $\left(F / F_{0}\right)$ evoked by rapamycin recorded at a representative mitochondrion and in nearby reticular ER. Results show $\sim 80 \%$ loss of fluorescence from the ER devoid of mitochondrial contacts. $\mathbf{f}, \mathbf{g}$ HeLa cells co-expressing endogenously tagged GFP-IP ${ }_{3} R 1$, GNb-FKBP and mitochondrial TOM70-mCh-FRB were imaged using TIRFM. A representative cell $(n=6)$ is shown before $(\mathbf{f})$ and after $(\mathbf{g})$ treatment with rapamycin $(100 \mathrm{nM}, 10 \mathrm{~min})$. The boxed region is enlarged in subsequent images. Scale bars $10 \mu \mathrm{m}$ (main images) and $2.5 \mu \mathrm{m}$ (enlargements). $\mathbf{h}$ HeLa cells co-expressing GFP-calmodulin (GFP-CaM), GNb-FKBP and TOM20-mCh-FRB were imaged using epifluorescence microscopy. A representative cell $(n=3)$ is shown before and after treatment with rapamycin $(100 \mathrm{nM}, 10 \mathrm{~min})$. The image for TOM-mCh-FRB is shown in the presence of rapamycin. Scale bar $10 \mu \mathrm{m}$

accumulation of $\beta_{2} \mathrm{AR}$ at mitochondria in COS-7 cells expressing $\beta_{2}$ AR-GFP, TOM20-mCh-FRB and GNb-FKBP (Additional file 1: Figure S4). In similar analyses of ER-mitochondria and PM-mitochondria MCS, the initial punctate co-localization of proteins was shown to report native MCS, which grew larger with time as rapamycin zipped the proteins together [48]. Our results are consistent with that interpretation. In most cases, $\beta_{2} A R$ were recruited to only one or two discrete sites on each mitochondrion, which expanded during prolonged incubation with rapamycin, but without the appearance of new sites
(Fig. 12d, e, and Additional file 1: Figure S4). Rapamycin had no evident effect on recruiting new mitochondria to the PM, but it did cause accumulation of tagged TOM70 at MCS and depletion of TOM70 from the rest of each mitochondrion, indicating mobility of TOM70 within the OMM (Additional file 1: Figure S4). Our results suggest that inducible crosslinking using RNb-FKBP or GNbFKBP identifies native MCS between mitochondria and PM, with each mitochondrion forming only one or two MCS with the PM. We have not explored the functional consequences of these restricted MCS, but we speculate 


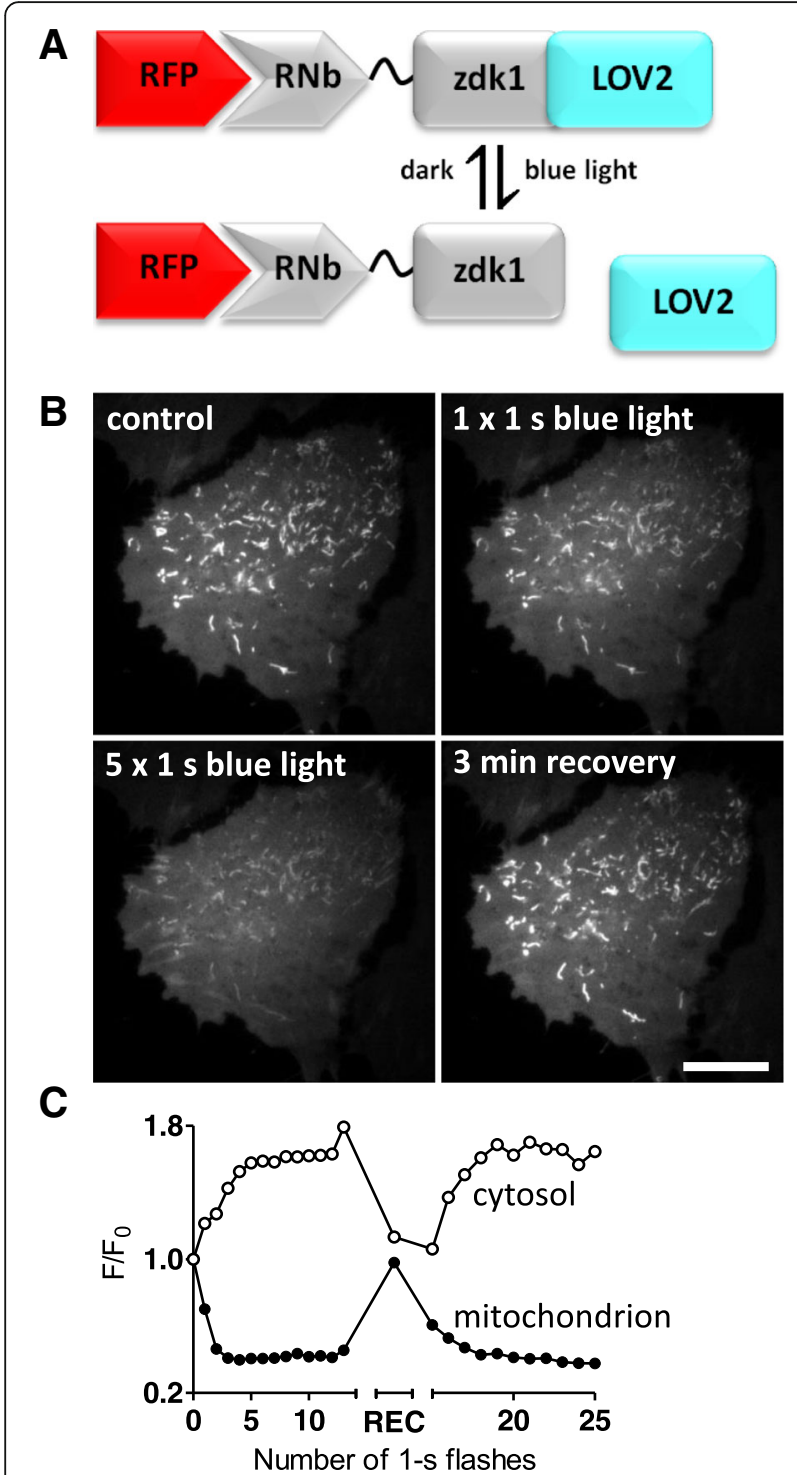

Fig. 11 Reversible optogenetic recruitment of RFP-tagged proteins using RNb-zdk1. a Schematic of RNb-zdk1 fusion bound to RFP, showing the reversible light-evoked dissociation of zdk1 from LOV2. $\mathbf{b}$ HeLa cells co-expressing RNb-zdk1, mitochondrial TOM20-LOV2 and cytosolic mCh were imaged using TIRFM. A representative cell is shown before and after one or five 1-s exposures to blue light (488-nm laser at 2-s intervals) and after a 3-min recovery period in the dark. Scale bar $10 \mu \mathrm{m}$. c Timecourse of the mCherry fluorescence changes $\left(F / F_{0}\right)$ recorded at a representative mitochondrion and in nearby cytosol after each of the indicated light flashes. There is a reversible decrease $(\sim 60 \%)$ in mitochondrial mCh fluorescence and a corresponding reversible increase $(\sim 70 \%)$ in cytosolic fluorescence. A single measurement of $\mathrm{mCh}$ fluorescence was made at the end of a 3-min recovery period in the dark (REC) before further light flashes. Results are representative of 5 cells from 3 independent experiments that they may identify sites where proteins involved in communication between the PM and mitochondria are concentrated, facilitating, for example, phospholipid transfer [49], the generation of ATP microdomains [50], or $\mathrm{Ca}^{2+}$ exchanges between mitochondria and store-operated $\mathrm{Ca}^{2+}$ entry (SOCE) [51] or PM Ca ${ }^{2+}$-ATPases [52].

We next tested whether PM proteins could be recruited to the MCS between ER-PM that are important for SOCE and lipid transfer [53]. In response to rapamycin, mCh-Orail, the $\mathrm{PM} \mathrm{Ca}^{2+}$ channel that mediates SOCE [54], was recruited by RNb-FKBP to ER-PM MCS labelled with the marker GFP-MAPPER-FRB [55] (Fig. 13a, b). Recruitment was not observed in the absence of RNb-FKBP (Fig. 13c). We conclude that the method identifies native ER-PM MCS during the initial phase of $\mathrm{Nb}$ recruitment, and the $\mathrm{Nb}$ subsequently exaggerates these MCS.

One of the least explored MCS is that between lysosomes and mitochondria [56]. Recent evidence shows that these MCS control the morphology of both organelles [57] and probably mediate the exchange of cholesterol and other metabolites between them [58]. We assessed whether the nanobody fusions could be used to inducibly recruit lysosomes to mitochondria. GNb-FKBP enabled recruitment of lysosomes labelled with LAMP1-GFP to mitochondria labelled with TOM20-mCh-FRB, in response to rapamycin (Fig. 14a-c). Lysosomes were not recruited to mitochondria in the absence of GNb-FKBP (Fig. 14d).

\section{Crosslinking RFP-tagged and GFP-tagged proteins}

We generated a dimeric nanobody (GNb-RNb) that binds simultaneously to GFP and RFP (Fig. 15a) and demonstrated its utility by crosslinking a variety of GFP-tagged and RFP-tagged proteins. Cytosolic GFP, normally diffusely distributed in the cytosol (data not shown), was recruited to nuclei by H2B-mCh (Fig. 15b) or to mitochondria by TOM20-mCh (Fig. 15c). In the presence of GNb-RNb, mCh-Orail and endogenously tagged GFP-IP ${ }_{3} \mathrm{R} 1$ formed large co-clusters (Fig. 15d) that differed markedly from the distributions of GFP- $\mathrm{IP}_{3} \mathrm{R} 1$ (Fig. 10f) and mCh-Orai1 (Fig. 13) in the absence of crosslinking. Consistent with earlier results (Fig. 12 and Additional file 1: Figure S4), $\beta_{2} \mathrm{AR}-\mathrm{mCh}$, which is normally diffusely distributed in the PM, formed mitochondria-associated puncta when crosslinked to mitochondria expressing TOM20-GFP (Fig. 15e). Whole organelles could also be crosslinked. Co-expression of LAMP1-GFP and LAMP1-mCh labelled small, mobile lysosomes in control cells (Fig. 15f), while additional co-expression of GNb-RNb caused accumulation of lysosomes into large clusters (Fig. 15g).

This crosslinking of GFP and RFP was made rapidly inducible with an RNb-FRB fusion that hetero-dimerizes with GNb-FKBP in the presence of rapamycin (Fig. 16a). Co-expression of GNb-FKBP with RNb-FRB in cells 


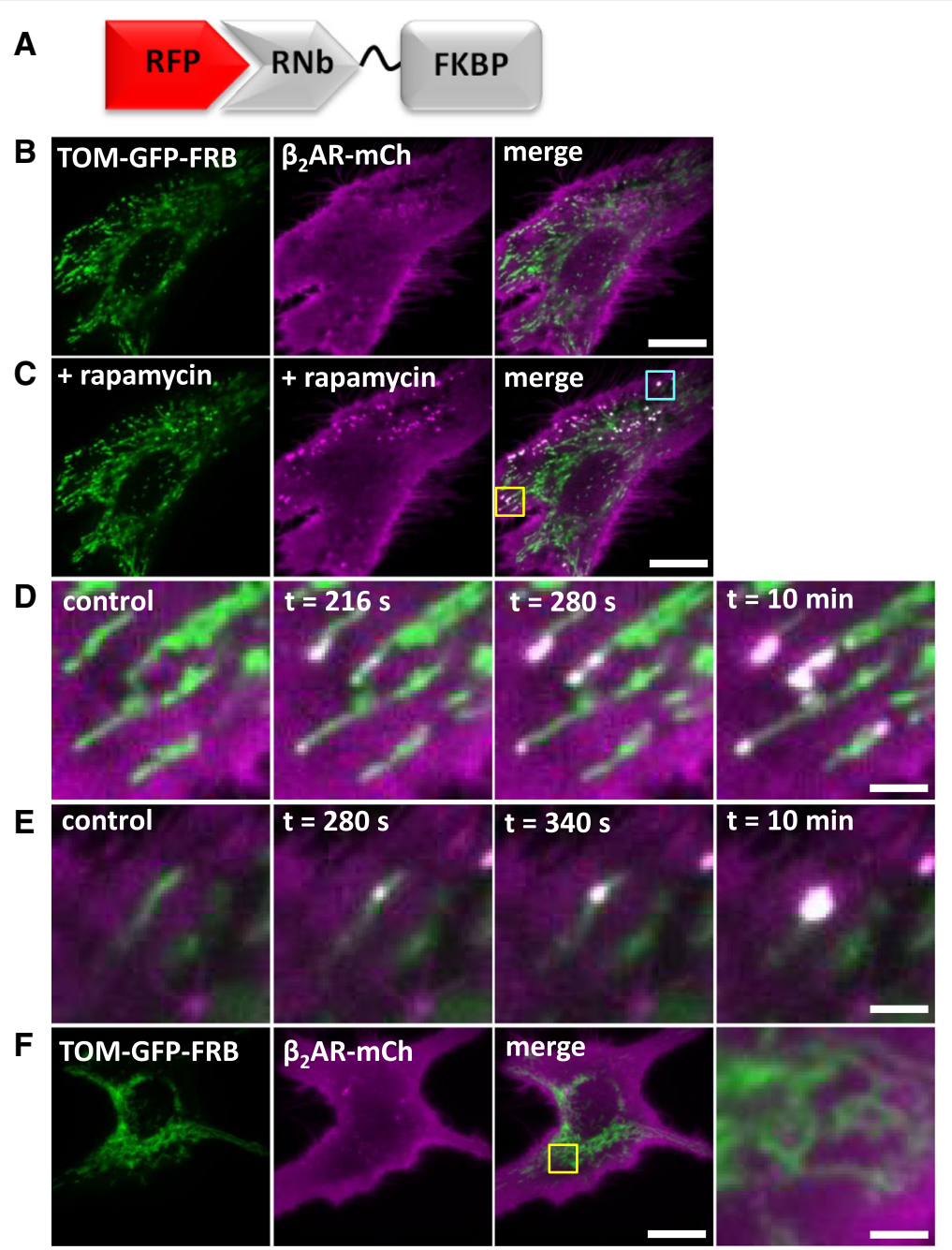

Fig. 12 Recruitment of proteins to native PM-mitochondria MCS using RNb-FKBP. a Schematic of RNb-FKBP fusion bound to RFP. b, c HeLa cells co-expressing RNb-FKBP, mitochondrial TOM70-GFP-FRB and $\beta_{2}$ AR-mCh were imaged using TIRFM before (b) and after (c) treatment with rapamycin (100 nM, $10 \mathrm{~min}$ ). Scale bar $10 \mu \mathrm{m}$. d, e Enlarged images from $C$ of the yellow box (d) and cyan box (e) show punctate recruitment of $\beta_{2} A R-m C h$ to individual mitochondria at the indicated times after addition of rapamycin. Scale bars $1.25 \mu \mathrm{m}$. f TIRFM images of HeLa cells co-expressing mitochondrial TOM70-GFP-FRB and $\beta_{2}$ AR-mCh in the presence of rapamycin (100 nM, $10 \mathrm{~min}$ ) show no recruitment in the absence of co-expressed RNb-FKBP. The yellow box shows a region enlarged in the subsequent image. Scale bars $10 \mu \mathrm{m}$ (main images) and $2.5 \mu \mathrm{m}$ (enlargement). Results (b-f) are representative of 5 independent experiments

co-expressing TOM20-GFP and $\mathrm{mCh}-\mathrm{Sec} 61 \beta$ led to rapid colocalization of GFP and $\mathrm{mCh}$ after addition of rapamycin (Fig. 16b, c, and Additional file 9: Video 8). Similar results were obtained with RNb-FKBP and GNb-FRB (Additional file 1: Figure S5). We conclude that GNb-FKBP and RNb-FRB provide a rapidly inducible system for crosslinking any GFP-tagged protein to any RFP-tagged protein.

\section{Targeting secretory compartments with lumenal nanobodies}

$\mathrm{GNb}$ and $\mathrm{RNb}$ were directed to the lumen of the secretory pathway by addition of an N-terminal signal sequence, giving ssGNb and ssRNb. Targeting of ssGNb-mCh to the
Golgi, ER network or ER-PM MCS was achieved by co-expression of organelle markers with lumenal FP tags (Fig. 17a, b). In each case, there was significant colocalization of green and red proteins. Similar targeting of ssRNb-GFP to the ER network or ER-PM MCS was achieved by co-expression with $\mathrm{mCh}$-tagged lumenal markers of these organelles (Fig. 17c, d). These results demonstrate that $\mathrm{ssGNb}$ and $\mathrm{ssRNb}$ fusions can be directed to the lumen of specific compartments of the secretory pathway.

Fluorescent $\mathrm{Ca}^{2+}$ sensors targeted to the lumen of the entire ER $[59,60]$ are widely used and have considerably advanced our understanding of $\mathrm{Ca}^{2+}$ signalling $[61,62]$. Fluorescent $\mathrm{Ca}^{2+}$ sensors targeted to ER sub-compartments 


\section{A}
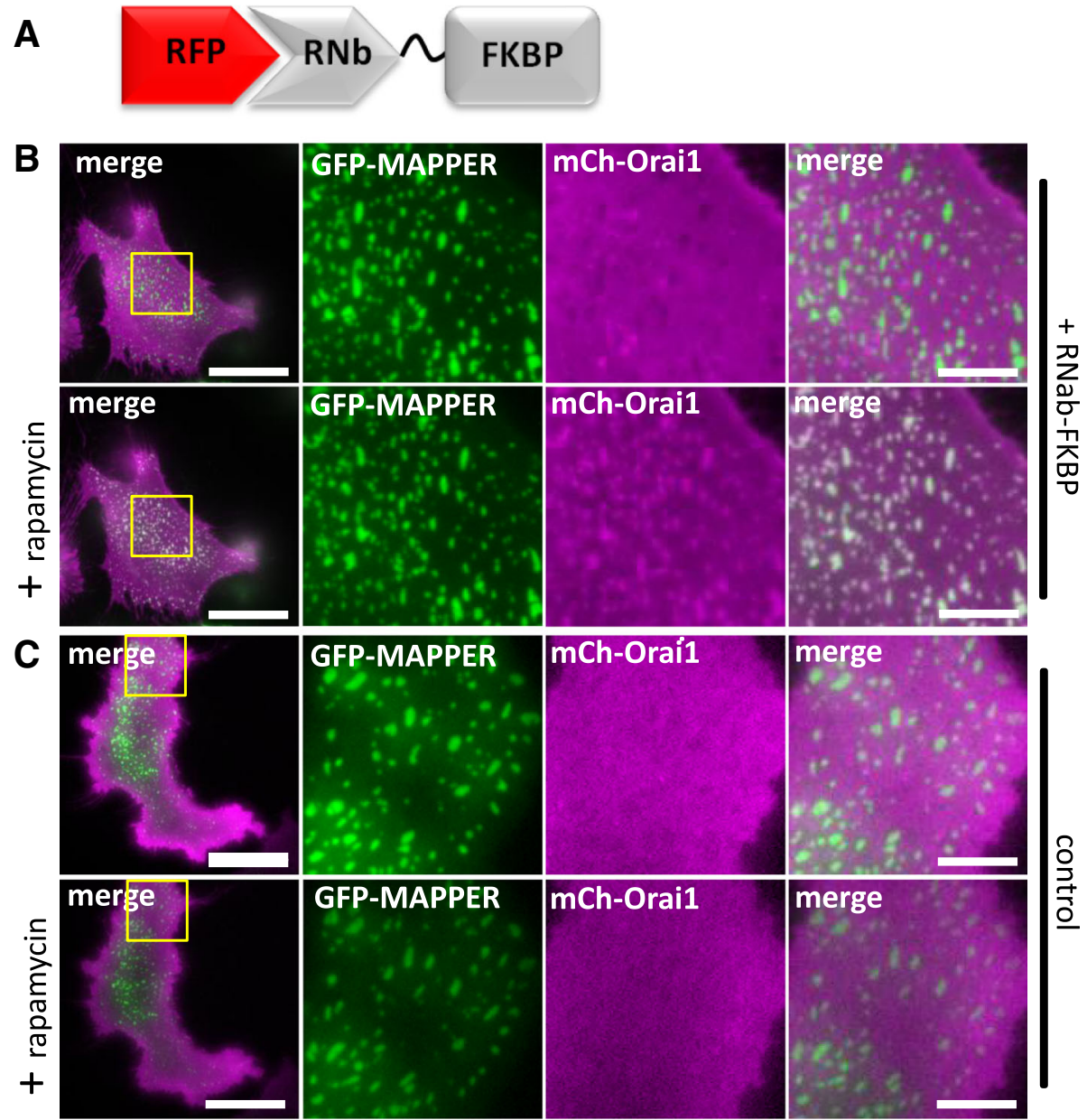

Fig. 13 Recruitment of PM proteins to ER-PM MCS using RNb-FKBP. a Schematic of RNb-FKBP fusion bound to RFP. b HeLa cells co-expressing RNb-FKBP, mCh-Orai1 and the ER-PM junction marker GFP-MAPPER-FRB were imaged using TIRFM. A representative cell $(n=5)$ is shown before (top row) and after (bottom row) treatment with rapamycin (100 nM, $10 \mathrm{~min})$. The boxed region is shown enlarged in subsequent images. c HeLa cells co-expressing mCh-Orai1 and GFP-MAPPER-FRB alone were imaged using TIRFM. A representative cell $(n=3)$ is shown before (top row) and after (bottom row) treatment with rapamycin (100 nM, $10 \mathrm{~min}$ ). The boxed region is shown enlarged in subsequent images. The results show no recruitment in the absence of co-expressed RNb-FKBP. Scale bars (b, c) $10 \mu \mathrm{m}$ (main images) and $2.5 \mu \mathrm{m}$ (enlargements)

and the secretory pathway have received less attention but have, for example, been described for the Golgi [63, 64]. Our nanobody methods suggest a generic approach for selective targeting of lumenal $\mathrm{Ca}^{2+}$ indicators. Fusion of ssRNb to GCEPIA1 or GEMCEPIA [60] provided ssRNb-GCEPIA1 and ssRNb-GEMCEPIA (Fig. 18a). These fusions were targeted to the lumenal aspect of ER-PM junctions by co-expression with mCh-MAPPER [7] (Fig. 18c, d). Fusion of ssGNb to the low-affinity $\mathrm{Ca}^{2+}$ sensors LAR-GECO1 [59] or RCEPIA1 [60] provided ssGNb-LARGECO1 and ssGNb-RCEPIA1 (Fig. 18b). These fusions allowed targeting to ER-PM junctions labelled with GFP-MAPPER (Fig. 18e, f). The targeted $\mathrm{Ca}^{2+}$ sensors responded appropriately to emptying of intracellular $\mathrm{Ca}^{2+}$ stores by addition of ionomycin in $\mathrm{Ca}^{2+}-$ free medium (Fig. 18g-k). These results confirm that $\mathrm{Ca}^{2+}$ sensors targeted to a physiologically important ER sub-compartment, the ER-PM junctions where SOCE occurs, report changes in lumenal $\left[\mathrm{Ca}^{2+}\right]$. Our results demonstrate that nanobody fusions can be targeted to lumenal sub-compartments of the secretory pathway and they can report $\left[\mathrm{Ca}^{2+}\right]$ within physiologically important components of the ER.

\section{Discussion}

The spatial organization of the cell interior influences all cellular activities, and it is a recurrent theme in intracellular signalling $[65,66]$. Hence, tools that can visualize and manipulate the spatial organization of intracellular components are likely to find widespread application. We introduce a toolkit of plasmids encoding functionalized nanobodies against common FP tags, including CFP, GFP, YFP and RFPs (Fig. 1). Use of this toolkit is supported by genome-wide collections of plasmids, cells and organisms 


\section{A

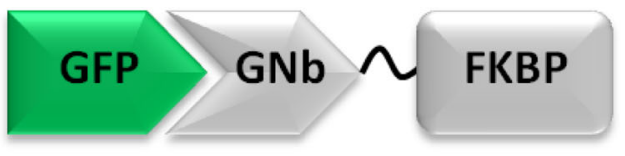

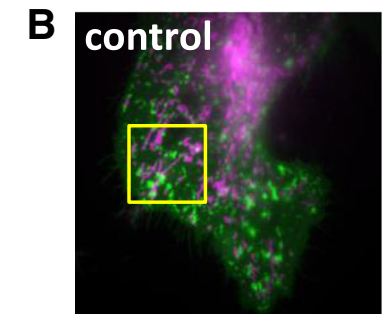
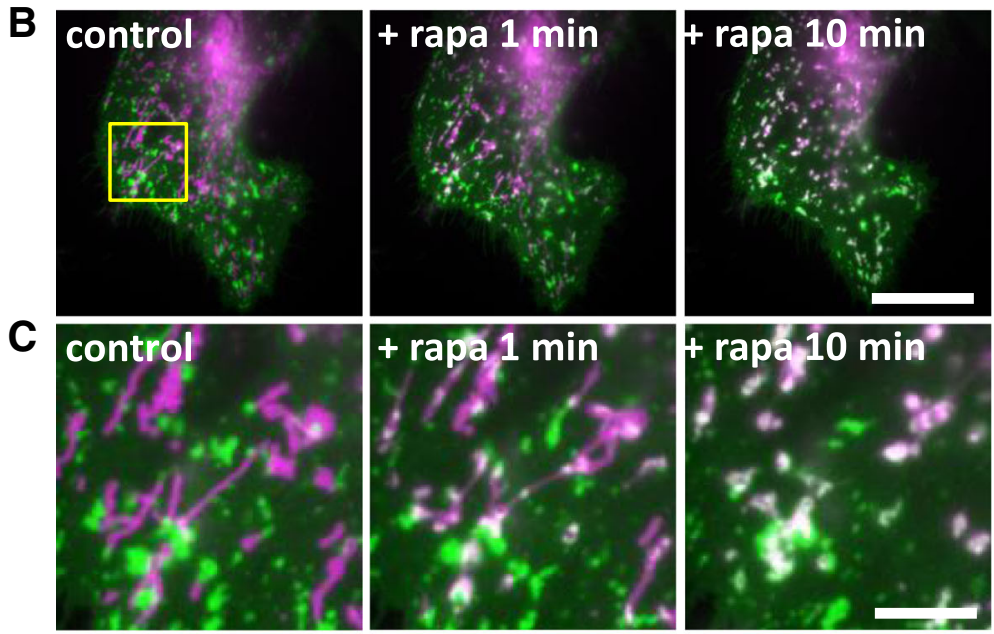

D
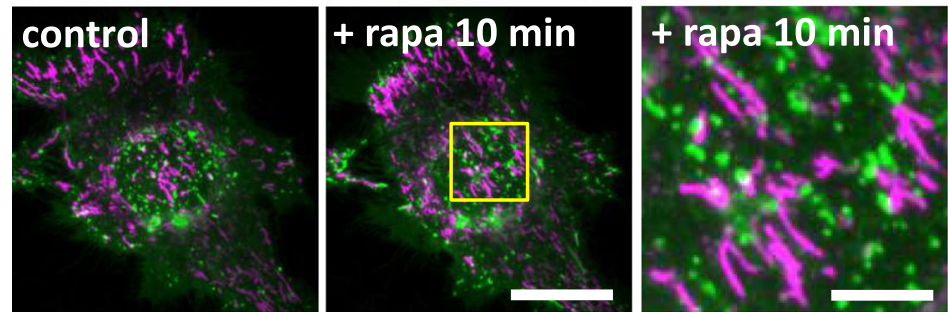

Fig. 14 Inducible recruitment of lysosomes to mitochondria using GNb-FKBP. a Schematic of GNb-FKBP fusion bound to GFP. b HeLa cells coexpressing mitochondrial TOM70-mCh-FRB (magenta), lysosomal LAMP1-GFP (green) and GNb-FKBP were imaged using TIRFM. Merged images of a representative cell $(n=5)$ are shown before and at times after treatment with rapamycin (rapa, $100 \mathrm{nM})$. Scale bar $10 \mu \mathrm{m}$. c Enlargements of the boxed region in $\mathbf{b}$. Scale bar $2.5 \mu \mathrm{m}$. $\mathbf{d}$ HeLa cells co-expressing TOM70-mCh-FRB (magenta) and lysosomal LAMP1-GFP (green) were imaged using TIRFM. A representative cell $(n=3)$ is shown before and after treatment with rapamycin $(100 \mu \mathrm{m}, 10 \mathrm{~min})$; there is no recruitment in the absence of co-expressed GNb-FKBP. The yellow box shows a region enlarged in the subsequent image. Scale bars $10 \mu \mathrm{m}$ (main images) and $2.5 \mu \mathrm{m}$ (enlargement)

expressing proteins tagged with GFP and RFP $[10-17,19]$ and by facile methods for heterologous expression of tagged proteins or editing of endogenous genes to encode FP tags [5, 6]. The functionalized nanobodies provide new approaches to studying intracellular signalling in live cells.

Our toolkit expands the repertoire of functionalized RFP-binding nanobodies, which are less developed than their GFP-binding counterparts [67]. The RNb fusions provide new opportunities to use RFP, which often has advantages over GFP. For example, RFP is spectrally independent from blue-green sensors, which are usually superior to their red counterparts [30, 32]; from the CALI probe, fluorescein; and from optogenetic modules, which are often operated by blue-green light [68].

Nanobody-sensor fusions allow targeting of sensors to specific proteins and organelles (Figs. 2, 3, 4, 5 and 6) and will aid visualization of signalling within cellular microdomains. Fusion of nanobodies to the $\mathrm{Ca}^{2+}$ sensors G-GECO1.2, R-GECO1.2 and LAR-GECO1.2 [30] (Figs. 3 and 4), which have relatively low affinities for $\mathrm{Ca}^{2+}\left(K_{D}\right.$ values of $1.2 \mu \mathrm{M}, 1.2 \mu \mathrm{M}$ and $10 \mu \mathrm{M}$, respectively), should facilitate selective detection of the relatively large, local rises in $\left[\mathrm{Ca}^{2+}\right]_{\mathrm{c}}$ that are important for cell signalling [27]. The GEM-GECO $\mathrm{Ca}^{2+}$ sensor [30], $\mathrm{H}^{+}$sensors $[31,32]$ and ATP/ADP sensors [33] used for nanobody fusions are poised to detect fluctuations of their ligands around resting concentrations in the cell (Figs. 4, 5 and 6).

Relative to direct fusions of sensors to proteins of interest, nanobody-sensor fusions have several advantages. Firstly, the generic nanobody toolkit (Fig. 1) can be combined with collections of FP-tagged proteins to provide many combinations; each would otherwise require the expression of a unique construct that may or may not function normally. Secondly, each sensor is attached to the same entity (nanobody), which binds to the same partner (FP). Since the biophysical and biochemical properties of sensors may be influenced by their fusion partners, this 


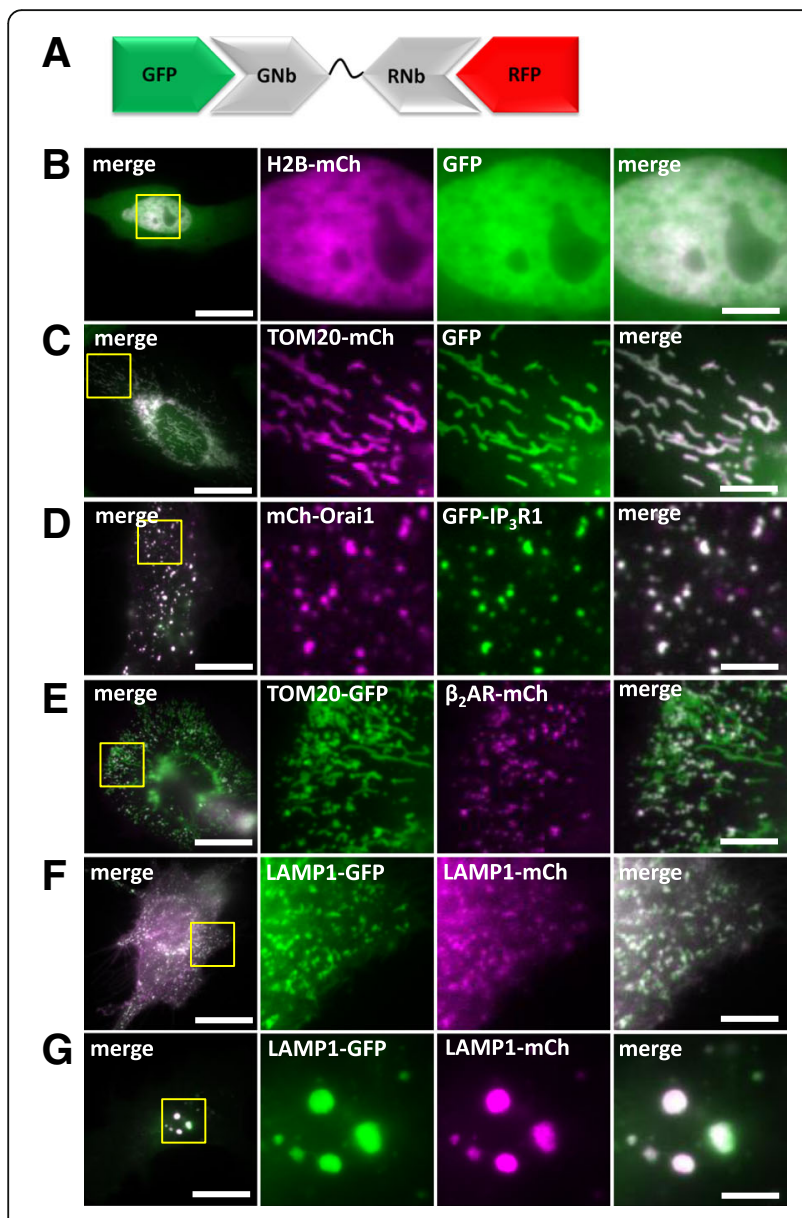

Fig. 15 Crosslinking GFP-tagged and RFP-tagged proteins and organelles using GNb-RNb. a Schematic of GNb-RNb bound to GFP and RFP. b-e HeLa cells co-expressing the tagged proteins indicated with GNb-RNb were imaged using epifluorescence microscopy (b) or TIRFM (c-e). Representative cells $(n=5-7)$ are shown. Control images for GFP-IP ${ }_{3} R 1$ are shown in Fig. 10 and Additional file 1: Figure S3. f, $\mathbf{g}$ HeLa cells co-expressing LAMP1-GFP and LAMP1-mCh in the absence $(\mathbf{f})$ or presence $(\mathbf{g})$ of co-expressed GNb-RNb were imaged using TIRFM. Representative cells $(n=5)$ are shown. Scale bars (b-g) $10 \mu \mathrm{m}$ (main images) and $2.5 \mu \mathrm{m}$ (enlargements of boxed areas)

provides greater confidence that sensors despatched to different locations will respond similarly to their analyte.

Nanobodies allow re-colouring of FPs with alternative fluorophores that may have advantageous properties. For example, re-colouring of RFP-tagged proteins with RNb-GFP (Fig. 2b) enables visualization of organelles with GFP, which has enhanced photophysical properties relative to RFPs. Nanobody-SNAPf fusions can be used to attach fluorescent dyes, including CALI probes and far-red fluorophores, to FP tags (Figs. 7 and 8). Longer excitation wavelengths cause less phototoxicity and allow greater penetration through tissue, which may be useful in studies of transgenic organisms and tissues. We also envisage live-cell applications in pulse-chase analyses and using super-resolution microscopy, Förster resonance energy transfer (FRET) and fluorescence lifetime imaging.

Membrane-permeant forms of the SNAP ligand, $\mathrm{O}^{6}$-benzylguanine, are available conjugated to conventional $\mathrm{Ca}^{2+}$ indicators (Fura-2FF, Indo-1 and BOCA-1), which are brighter than genetically encoded indicators [69-71]; to derivatives of the two-photon fluorophore naphthalimide [72]; to the hydrogen peroxide sensor nitrobenzoylcarbonylfluorescein [73]; and to reversible chemical dimerizers $[74,75]$. Nanobody-SNAPf fusions will allow facile targeting of these modules to any protein or organelle tagged with RFP or GFP.

Crosslinking methods have many applications in cell biology, including stabilizing protein interactions (e.g. for pull-downs), identifying and manipulating MCS, enforcing protein interactions (e.g. receptor dimerization), redirecting proteins to different subcellular locations (e.g. knocksideways) and many more. Functionalized nanobodies provide many additional opportunities to regulate protein associations. The nanobody-FKBP/FRB fusions, for example, allow rapid rapamycin-mediated crosslinking of any pair of proteins tagged with GFP/RFP or tagged with either FP and any of the many proteins already tagged with FKBP or FRB [76] (Figs. 10, 12, 13, 14, 15, and 16). Nanobody-FKBP fusions may allow crosslinking to SNAP-tagged proteins [75], and the nanobody-SNAPf fusions to HaloTag-tagged proteins [74] and FKBP-tagged proteins [75]. RNb-zdk1 fusions allow photo-inducible crosslinking of RFP-tagged proteins to LOV-tagged proteins [46] (Fig. 11). Nanobodies that crosslink GFP-tagged proteins to RFP-tagged proteins $(\mathrm{GNb}-\mathrm{RNb}$; and the GNb-FKBP/RNb-FRB and GNb-FRB/RNb-FKBP pairings) may have the most applications, as they can take the fullest advantage of the numerous combinations of existing RFP and GFP-tagged proteins (Figs. 15 and 16).

Functionalized nanobodies directed to lumenal compartments of the secretory pathway would provide useful tools, but they are under-developed. Their potential is shown by nanobodies retained within the ER, which restrict onward trafficking of target proteins and inhibit their function [77]. We show that functionalized nanobodies, including nanobody- $\mathrm{Ca}^{2+}$ sensors, can be directed to sub-compartments of the secretory pathway (Figs. 17 and 18). Lumenal $\mathrm{Ca}^{2+}$ provides a reservoir within the ER, Golgi and lysosomes that can be released by physiological stimuli to generate cytosolic $\mathrm{Ca}^{2+}$ signals $[78,79]$. Compartmentalization of $\mathrm{Ca}^{2+}$ stores within the ER [63] and Golgi [79] adds to the complexity of lumenal $\mathrm{Ca}^{2+}$ distribution in cells. Furthermore, lumenal $\mathrm{Ca}^{2+}$ itself regulates diverse aspects of cell biology, including SOCE [54], sorting of cargo in the Golgi [80], binding of ERGIC-53 to cargoes within the ER-Golgi intermediate compartment (ERGIC) [81], and exocytosis of neurotransmitters by 
A
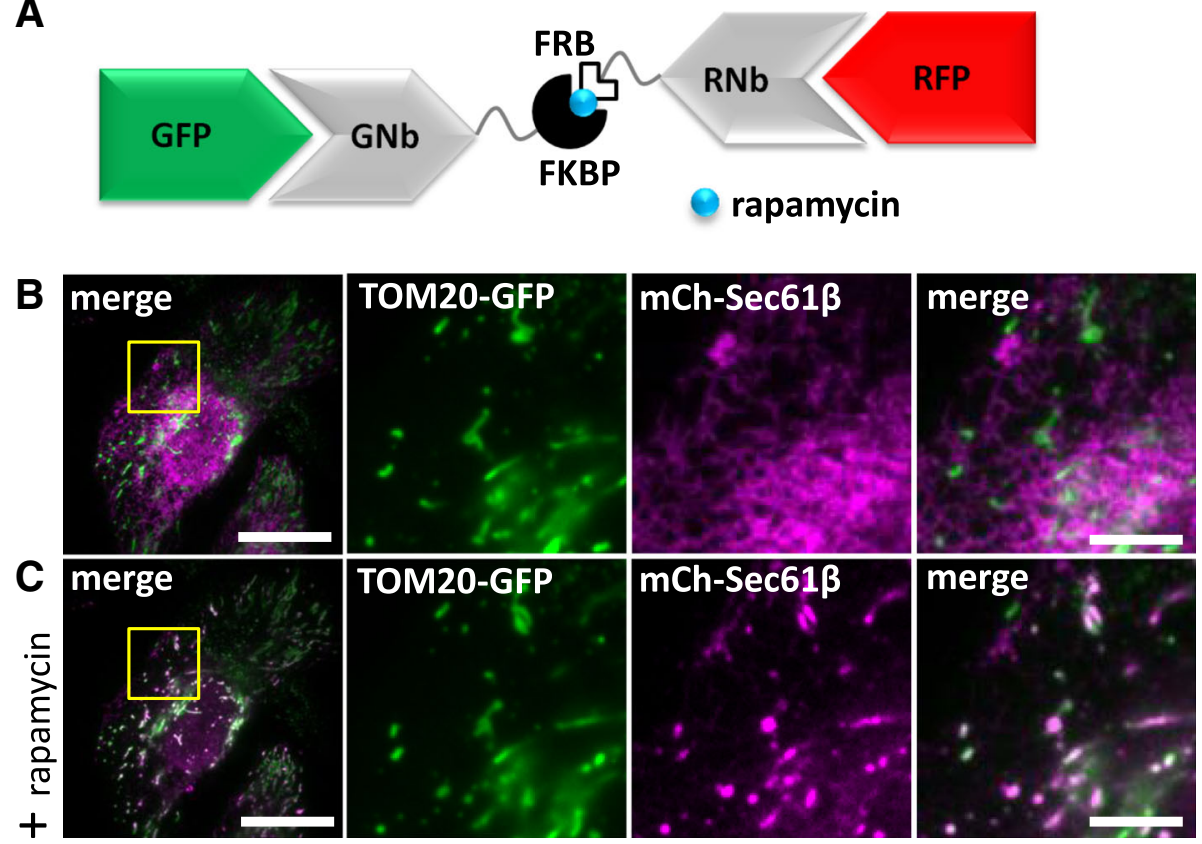

Fig. 16 Inducible crosslinking of RFP-tagged and GFP-tagged proteins with GNb-FKBP and RNb-FRB. a Schematic of the nanobody fusions used, with rapamycin shown as a blue sphere. b, $\mathbf{c}$ HeLa cells co-expressing GNb-FKBP, RNb-FRB, TOM20-GFP and mCh-Sec61 $\beta$ were imaged using TIRFM. A representative cell $(n=3)$ is shown before $(\mathbf{b})$ and after $(\mathbf{c})$ treatment with rapamycin $(100 \mathrm{nM}, 10 \mathrm{~min})$. Scale bars $10 \mu \mathrm{m}$ (main images) and $2.5 \mu \mathrm{m}$ (enlargements of boxed areas)

secretory vesicles $[82,83]$. Hence, there is a need for tools that can effectively report lumenal $\left[\mathrm{Ca}^{2+}\right]$ within this complex lumenal environment. The lumenal nanobody- $\mathrm{Ca}^{2+}$ sensors detected changes in lumenal $\left[\mathrm{Ca}^{2+}\right]$ at the ER-PM MCS where SOCE occurs (Fig. 18).

In addition to nanobodies, other protein-based binders, including single-domain antibodies, designed ankyrin-repeat proteins (DARPins), affimers, anticalins, affibodies and monobodies have been developed to recognise many important intracellular proteins [2, 84-86]. These binding proteins can be easily transplanted into the fusion scaffolds described to maximize their exploitation.

\section{Conclusions}

We present a toolkit of plasmids encoding functionalized nanobodies directed against common fluorescent protein tags, which will allow a wide range of applications and new approaches to studying intracellular signalling in live cells. We illustrate some applications and demonstrate, for example, that $\mathrm{IP}_{3}$ receptors deliver $\mathrm{Ca}^{2+}$ to the OMM of only some mitochondria and that MCS between mitochondria and the plasma membrane occur at only one or two sites on each mitochondrion.

\section{Materials and methods}

\section{Materials}

Human fibronectin was from Merck Millipore. Ionomycin was from Apollo Scientific (Stockport, UK). Rapamycin was from Cambridge Bioscience (Cambridge, UK). SNAP substrates were from New England Biolabs (Hitchin, UK). Other reagents, including histamine and nigericin, were from Sigma-Aldrich.

\section{Plasmids}

Sources of plasmids encoding the following proteins were mCherry-C1 (Clontech \#632524); mCherry-N1 (Clontech \#632523); EGFP-N1 (Clontech \#6085-1); GFP-ERcyt, mCherry-ERcyt and mTurquoise2-ERcyt (GFP, mCherry or mTurquoise2 targeted to the cytosolic side of the ER membrane via the ER-targeting sequence of the yeast UBC6 protein) [87]; mCherry-ERlumen (Addgene \#55041, provided by Michael Davidson); LAMP1-mCherry [88]; TPC2-mRFP [89]; TOM20-mCherry (Addgene \#55146, provided by Michael Davidson); CIB1-mRFP-MP (Addgene \#58367) [44]; CIB1-mCerulean-MP (Addgene \#58366) [44]; H2B-GFP (Addgene \#11680) [90]; TOM20-LOV2 (Addgene \#81009) [46]; mCherry-Sec61ß [91]; GFP-MAPPER [55]; GFP-CaM (Addgene \#47602, provided by Emanuel Strehler); TOM70mCherry-FRB (pMito-mCherry-FRB, Addgene \#59352) [92]; pmTurquoise2-Golgi (Addgene \#36205) [93]; pTriExmCherry-zdk1 (Addgene \#81057) [46]; pTriEx-NTOM20LOV2 (Addgene \#81009) [46]; $\beta_{2}$ AR-mCFP (Addgene \#38260) [94]; pCMV-G-CEPIA1er (Addgene \#58215) [60]; pCMV-R-CEPIA1er (Addgene \#58216) [60]; pCISGEMCEPIA1er (Addgene \#58217) [60]; CMV-ER-LAR- 

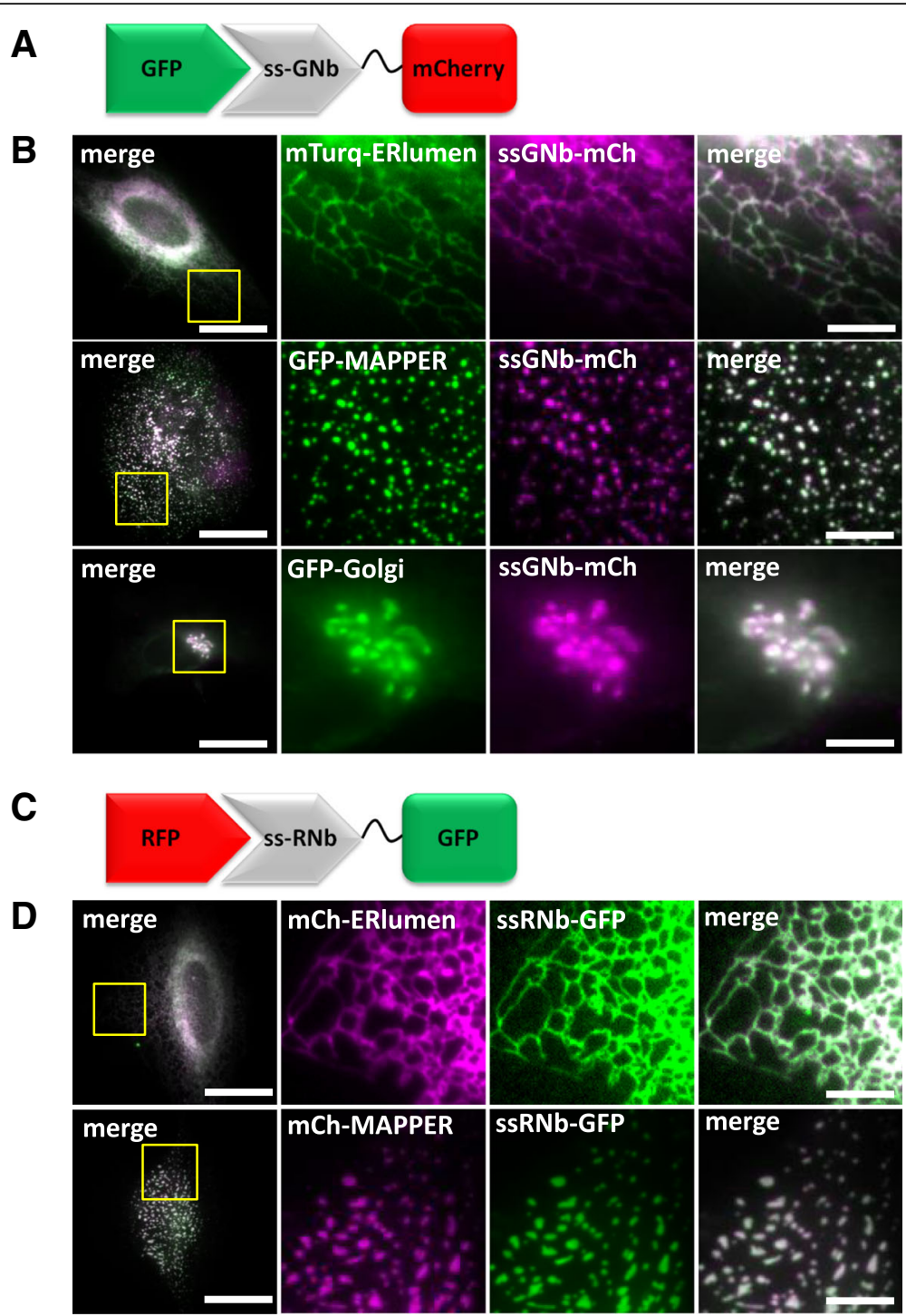

Fig. 17 Nanobody fusions can be targeted to different lumenal compartments of the secretory pathway. a Schematic of ssGNb-mCh bound to GFP. $\mathbf{b}$ HeLa cells co-expressing ssGNb-mCh and either the lumenal ER marker mTurquoise2-ERlumen, the marker of ER-PM junctions GFPMAPPER, or the Golgi marker GFP-Golgi. Cells were imaged using epifluorescence microscopy. Representative cells are shown. Colocalization values were mTurquoise2-ERlumen ( $r=0.96 \pm 0.03, n=10)$; GFP-MAPPER $(r=0.94 \pm 0.02, n=5)$; and GFP-Golgi $(r=0.91 \pm 0.06, n=4)$. c Schematic of ssRNb-GFP bound to RFP. $\mathbf{d}$ HeLa cells co-expressing ssRNb-GFP and either mCh-ERlumen or mCh-MAPPER were imaged using epifluorescence microscopy. Representative cells are shown. Colocalization values were: $\mathrm{mCh}$-ERlumen $(r=0.98 \pm 0.009, n=9)$ and $\mathrm{mCh}-\mathrm{MAPPER}(r=0.93 \pm 0.07, n=13$. Scale bars $10 \mu \mathrm{m}$ (main images) and $2.5 \mu \mathrm{m}$ (enlargements of boxed regions)

GECO1 and CMV-mito-LAR-GECO1.2 [59]; mCherryMAPPER and mCherry-Orai1 [7].

H2B-mCh was made by transferring H2B from H2B-GFP to pmCherry-N1 (Clontech) using KpnI/BamHI. LAMP1GFP was made by transferring LAMP1 from LAMP1mCherry into pEGFP-N1 (Clontech) using EcoRI/ BamHI. $\beta_{2}$ AR-mCherry was made by transferring $\beta_{2} \mathrm{AR}$ from $\beta_{2}$ AR-mCFP to pmCherry-N1 (Clontech) using NheI/XhoI. $\beta_{2}$ AR-GFP was made by transferring GFP

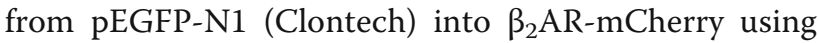
XhoI/NotI. The mCherry-Golgi plasmid was made by transferring mCherry from pmCherry-N1 into pEYFPGolgi (Clontech) using AgeI/NotI. GFP-Golgi was made by transferring GFP from pEGFP-N1 (Clontech) into Golgi-mCherry using AgeI/NotI. TOM20-GFP was made by transferring EGFP from pEGFP-N1 into TOM20-mCherry using BamHI/NotI. TOM70-GFPFRB was made by insertion of EGFP from pEGFP-N1 into TOM70-mCh-FRB using AgeI/BsrGI. SNAPfpcDNA3.1(+) was made by transferring SNAPf from pSNAPf (New England Biolabs) to pcDNA3.1 (+) using NheI/NotI. 


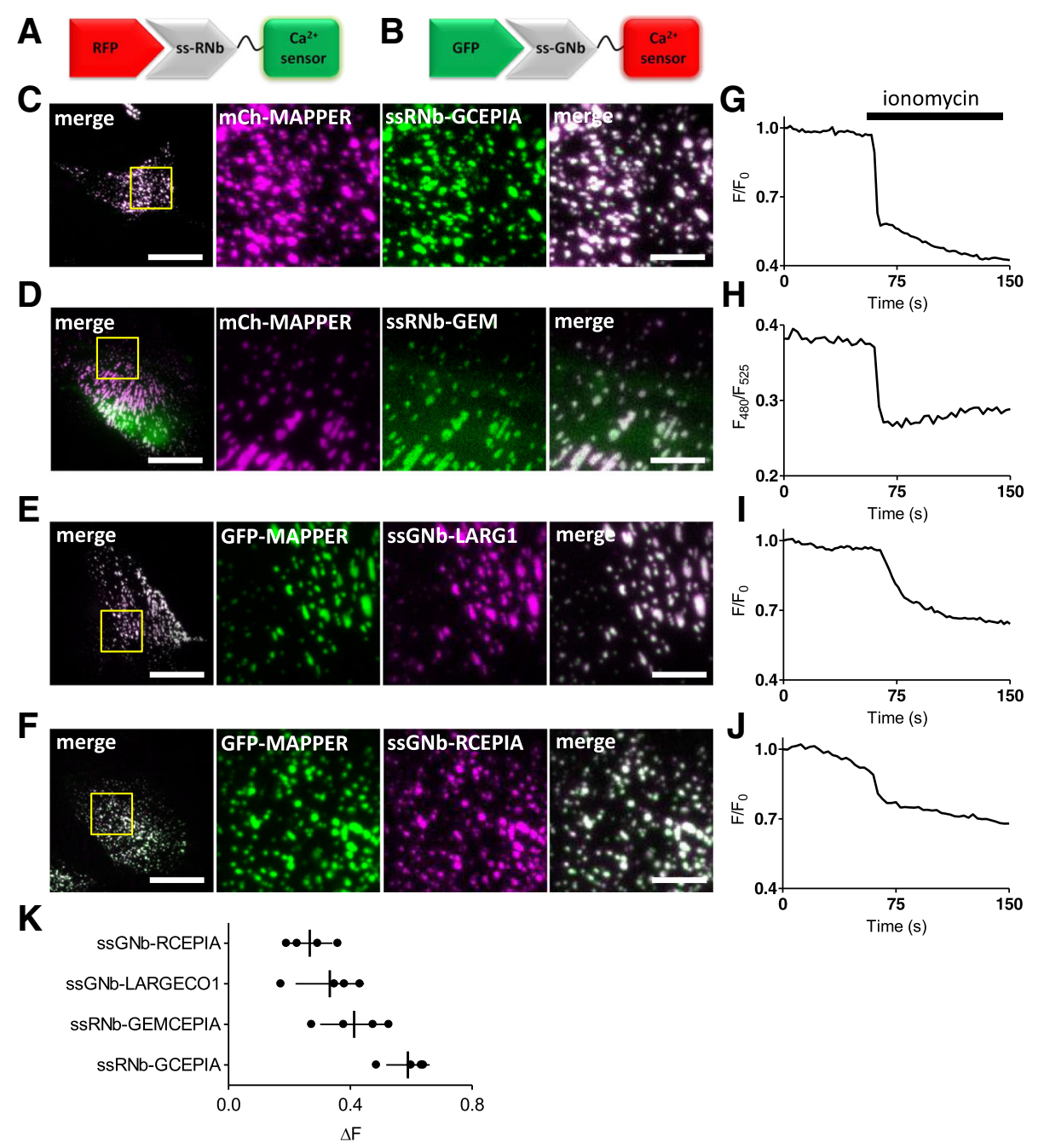

Fig. 18 Nanobody-mediated targeting of low-affinity $\mathrm{Ca}^{2+}$ sensors allows measurement of changes in $\left[\mathrm{Ca}^{2+}\right]$ in an ER sub-compartment at ER-PM MCS. a Schematic of ssRNb-Ca ${ }^{2+}$ sensor bound to RFP. $\mathbf{b}$ Schematic of ssGNb-Ca ${ }^{2+}$ sensor bound to GFP. $\mathbf{c}-\mathbf{f}$ HeLa cells co-expressing the indicated combinations of mCh-MAPPER, GFP-MAPPER, ssRNb-GCEPIA (ssRNb-GC), ssRNb-GEMCEPIA (ssRNb-GEM; the image is shown for the 525-nm emission channel), ssGNb-LAR-GECO1 (ssGNb-LGECO) or ssGNb-RCEPIA were imaged in $\mathrm{Ca}^{2+}$-free HBS using TIRFM. Yellow boxes indicate regions enlarged in subsequent images. Scale bars $10 \mu \mathrm{m}$ (main images) and $2.5 \mu \mathrm{m}$ (enlargements). $\mathbf{g}-\mathbf{j}$ Timecourses of fluorescence changes recorded from cells co-expressing mCh-MAPPER and ssRNb-GCEPIA (g), mCh-MAPPER and ssRNb-GEMCEPIA (h), GFP-MAPPER and ssGNb-LARGECO1 (ssGNb-LARG1) (i) and GFP-MAPPER and sSGNb-RCEPIA (j) in response to emptying of intracellular $\mathrm{Ca}^{2+}$ stores with ionomycin (5 $\mu$ M). $\mathbf{k}$ Summary results (with mean $\pm \mathrm{SD}, n=4$ cells) show fractional decreases $(\Delta F)$ in either fluorescence or emission ratio (for ssRNb-GEM) recorded $90 \mathrm{~s}$ after addition of ionomycin

DNA constructs encoding GNb and RNb were synthesized as DNA Strings (ThermoFisher) and introduced by Gibson assembly (Gibson Assembly Master Mix, New England Biolabs) into pcDNA3.1(+) digested with BamHI/EcoRI. Sequences encoding GNb and $\mathrm{RNb}$ are shown in Additional file 1: Figure S6. Plasmids encoding nanobody fusion constructs (Fig. 1) were constructed from the $\mathrm{GNb}$ and $\mathrm{RNb}$ plasmids using PCR, restriction digestion and ligation, or synthetic DNA Strings and Gibson assembly, and their sequences were confirmed.
GNb-mCherry was made by PCR of pmCherry-N1 using forward (ACTGGATCCATGGTGAGCAAGGGCGAG) and reverse (GTACTCGAGCTACTTGTACAG CTCGTCCATGC) primers, followed by insertion into GNb-pcDNA3.1(+) using BamHI/XhoI. RNb-GFP was made by PCR of pEGFP-N1 using forward (ACTGGATCCATGGTGAGCAAGGGCGAG) and reverse (GTACTCGAGCTACTTGTACAGCTCGTCCATGC) primers, followed by insertion into RNb-pcDNA3.1(+) using Bam HI/XhoI. RNb-mCerulean-MP was made by PCR of RNb using forward (ATGCTAGCAAGCTTGCCACCATGGCTC) 
and reverse (ATACCGGTGAGGATCCAGAGCCTCCGC) primers, followed by insertion into CIB1-mCerulean-MP using Nhel/AgeI. GNb-mRFP-MP was made by PCR of GNb-FKBP with forward (TAGCTAGCGCCACCATGGCTCAGGTG) and reverse (CGACCGGTACGGACACGGTCACTTGGG) primers, followed by insertion into CIB1-mRFP1-MP using Nhel/Agel. GNb-SNAPf and RNb-SNAPf were made by PCR of GNb-pcDNA3.1(+) and RNb-pCDNA3.1(+) using forward (CAGCTAGCTTGGTACCGAGCTCAAGCTTGC) and reverse (ATGAATTCAGATCCCCCTCCGCCAC) primers, followed by insertion into SNAPf-pcDNA3.1 $(+)$ using Nhel/ EcoRI. GNb-LAR-GECO1.2 was made by PCR of CMVmito-LAR-GECO1.2 using forward (CAGGATCCATGGTCGACTCTTCACGTCGTAAGTGG) and reverse (GTAC TCGAGCTACTTCGCTGTCATCATTTGTACAAACT) primers, followed by insertion into GNb-pcDNA3.1(+) using BamHI/XhoI. RNb-GGECO1.2 was made by PCR of CMV-G-GECO1.2 using forward (CAGGATCCATGGTCGACTCATCACGTCGTAAG) and reverse (TACGATGGGCCCCTACTTCGCTGTCATCATTTGTACAAACTCTTC) primers, followed by insertion into RNb-pcDNA3.1(+) using BamHI/ApaI. RNb-Perceval-HR was made by PCR of Perceval-HR with forward (AAGCGGCCGCTATGAAAAAGGTTGAATCCATCATCAGGCC) and reverse (ATCTCGAGTCACAGTGCTTCCTTGCCCTC) primers, followed by insertion into RNb-pcDNA3.1(+) using NotI/XhoI.

ssGNb-mCherry was made by inserting mCherry from GNb-mCherry into ssGNb-FKBP using BamHI/NotI. ssRNb-GFP was made by inserting GFP from RNb-GFP into ssRNb-pcDNA3.1(+) using BamHI/NotI. ssGNbRCEPIA was made by transferring RCEPIA from pCMVR-CEPIA1er to ssRNb-pcDNA3.1(+) using BamHI/NotI. ssGNb-LAR-GECO1 was made by transferring a DNA String encoding ssGNb into CMV-ER-LAR-GECO1 using HindIII/BamHI. ssRNb-GCEPIA was made by transferring GCEPIA from pCMV-G-CEPIAler to ssRNbpcDNA3.1(+) using BamHI/NotI. ssRNb-GEMCEPIA was made by transferring GEMCEPIA from pCIS-GEMCEPIA1er to ssRNb-pcDNA3.1(+) using BamHI/NotI.

\section{Cell culture and transient transfection}

HeLa and COS-7 cells (American Type Culture Collection) were cultured in Dulbecco's modified Eagle's medium/F-12 with GlutaMAX (ThermoFisher) supplemented with foetal bovine serum (FBS, 10\%, Sigma). Cells were maintained at $37^{\circ} \mathrm{C}$ in humidified air with $5 \% \mathrm{CO}_{2}$ and passaged every 3-4 days using Gibco TrypLE Express (ThermoFisher). For imaging, cells were grown on 35-mm glass-bottomed dishes (\#P35G-1.0-14-C, MatTek) coated with human fibronectin $\left(10 \mu \mathrm{g} \cdot \mathrm{ml}^{-1}\right)$. Cells were transfected, according to the manufacturer's instructions, using TransIT-LT1 (GeneFlow) (1 $\mu \mathrm{g}$ DNA per $2.5 \mu \mathrm{l}$ reagent). Short tandem repeat profiling
(Eurofins, Germany) was used to authenticate the identity of HeLa cells [7]. Screening confirmed that all cells were free of mycoplasma infection.

\section{Fluorescence microscopy and analysis}

Cells were washed prior to imaging at $20^{\circ} \mathrm{C}$ in HEPES-buffered saline (HBS: $\mathrm{NaCl} 135 \mathrm{mM}, \mathrm{KCl} 5.9 \mathrm{mM}$, $\mathrm{MgCl}_{2} 1.2 \mathrm{mM}, \mathrm{CaCl}_{2} 1.5 \mathrm{mM}$, HEPES $11.6 \mathrm{mM}$, D-glucose $11.5 \mathrm{mM}, \mathrm{pH} 7.3) . \mathrm{Ca}^{2+}$-free HBS lacked $\mathrm{CaCl}_{2}$ and contained EGTA (1 mM). For manipulations of intracellular $\mathrm{pH}$, cells were imaged in modified HBS (MHBS: $\mathrm{KCl}$ $140 \mathrm{mM}, \mathrm{MgCl}_{2} 1.2 \mathrm{mM}, \mathrm{CaCl}_{2} 1.5 \mathrm{mM}$, HEPES $11.6 \mathrm{mM}$, D-glucose $11.5 \mathrm{mM}, \mathrm{pH} 7.2)$. The $\mathrm{H}^{+} / \mathrm{K}^{+}$ionophore nigericin $(10 \mu \mathrm{M})$ was added 5 min before imaging to equilibrate intracellular and extracellular $\mathrm{pH}$, and the extracellular $\mathrm{pH}$ was then varied during imaging by exchanging the MHBS (pH 6.5 or $\mathrm{pH} 8$ ).

Fluorescence microscopy was performed at $20^{\circ} \mathrm{C}$ as described previously [7] using an inverted Olympus IX83 microscope equipped with a $\times 100$ oil-immersion TIRF objective (numerical aperture, NA 1.49), a multi-line laser bank (425, 488, 561 and $647 \mathrm{~nm})$ and an iLas2 targeted laser illumination system (Cairn, Faversham, Kent, UK). Excitation light was transmitted through either a quad dichroic beam splitter (TRF89902-QUAD) or a dichroic mirror (for $425 \mathrm{~nm}$; ZT442rdc-UF2) (Chroma). Emitted light was passed through appropriate filters (Cairn Optospin; peak/bandwidth: 480/40, 525/50, 630/75 and 700/ $75 \mathrm{~nm}$ ) and detected with an iXon Ultra 897 electron multiplied charge-coupled device (EMCCD) camera $(512 \times 512$ pixels, Andor). For TIRFM, the penetration depth was $100 \mathrm{~nm}$. The iLas2 illumination system was used for TIRFM and wide-field imaging. For experiments with RNb-Perceval-HR, a $\times 150$ oil-immersion TIRF objective (NA 1.45) and a Prime 95B Scientific metal-oxide-semiconductor (CMOS) camera $(512 \times 512$ pixels, Photometrics) were used.

For CALI and LOV2/zdk1 experiments, the 488-nm laser in the upright position delivered an output at the objective of $2.45 \mathrm{~mW}$ (PM100A power meter, Thor Labs, Newton, NJ, USA). For CALI, a single flash of 488-nm laser illumination (3-s duration) was applied, with 10-ms exposures to $488-\mathrm{nm}$ laser immediately before and after the CALI flash to allow imaging of SNAP-Cell-fluorescein (i.e. $3.02 \mathrm{~s}$ total CALI flash). For LOV2/zdk1 experiments, repeated flashes of 488-nm light (1-s duration each) were used at 2-s intervals to allow imaging with $561-\mathrm{nm}$ laser illumination during the intervening periods.

Before analysis, all fluorescence images were corrected for background by subtraction of fluorescence detected from a region outside the cell. Image capture and processing used MetaMorph Microscopy Automation and Image Analysis Software (Molecular Devices) and Fiji 
[95]. Particle tracking used the TrackMate ImageJ plugin [96], with an estimated blob diameter of 17 pixels and a threshold of 5 pixels. Co-localization analysis used the JACoP ImageJ plugin [97]. Pearson's correlation coefficient $(r)$ was used to quantify colocalization. We report $r$ values only when the Costes' randomization-based colocalization value ( $P$ value $=100$ after 100 iterations) confirmed the significance of the original colocalization. Where example images are shown, they are representative of at least three independent experiments (individual plates of cells from different transfections and days).

\section{Statistics}

Results are presented as mean \pm SEM for particle-tracking analyses and mean \pm SD for colocalization analyses, from $n$ independent analyses (individual plates of cells from different transfections). Statistical comparisons used paired or unpaired Student's $t$ tests, or analysis of variance with the Bonferroni correction used for multiple comparisons. ${ }^{*} P<0.05$ was considered significant.

\section{Additional files}

Additional file 1: Figure S1. Targeting RNb-GEMGECO $\mathrm{Ca}^{2+}$ sensor to RFP-tagged proteins. Figure S2. Targeting CALI to lysosomes with SNAPCell-fluorescein: cytosolic controls. Figure S3. Rapamycin alone does not recruit RFP-tagged or GFP-tagged proteins to mitochondria. Figure S4. Recruitment of proteins to native PM-mitochondria MCS using GNb-FKBP. Figure S5. Inducible crosslinking of RFP-tagged and GFP-tagged proteins with RNb-FKBP and GNb-FRB. Figure S6. DNA sequences encoding the nanobodies used. (PPTX $7375 \mathrm{~kb}$ )

Additional file 2: Video 1. RNb-GGECO1.2 detects changes in $\left[\mathrm{Ca}^{2+}\right]$ at the surface of mitochondria expressing TOM20-mCh. The top panel shows RNb-GGECO1.2 fluorescence (488-nm TIRFM excitation), and the bottom panel shows TOM20-mCh fluorescence (561-nm TIRFM excitation). In response to histamine $(100 \mu \mathrm{M}$, added at $60 \mathrm{~s})$, local rises in $\left[\mathrm{Ca}^{2+}\right]_{\mathrm{c}}$ were detected at the surfaces of individual mitochondria, but not in the bulk cytosol. lonomycin $(5 \mu \mathrm{M})$ was added at $3 \mathrm{~min}$. The video was acquired at $1 \mathrm{~Hz}$ and is shown at 30 frames per second (fps). The clock is in min:s. Relates to Fig. 3d. (MP4 $75 \mathrm{~kb}$ )

Additional file 3: Video 2. GNb-LARGECO1.2 detects local changes in $\left[\mathrm{Ca}^{2+}\right]$ at the surface of mitochondria expressing TOM20-GFP. The video shows GNb-LARGECO1.2 fluorescence (488-nm TIRFM excitation). Histamine (100 $\mu \mathrm{M}$, added at $60 \mathrm{~s})$ causes local rises in $\left[\mathrm{Ca}^{2+}\right]_{\mathrm{c}}$ at the OMM of individual mitochondria in the perinuclear region (cyan box in Fig. 4d), but not in peripheral regions (e.g. yellow box in Fig. $4 \mathrm{~d})$. Ionomycin ( $5 \mu \mathrm{M}$ ) was added at $3 \mathrm{~min}$. The video was acquired at $1 \mathrm{~Hz}$ and is shown at $33 \mathrm{fps}$. The clock is in min:s. Relates to Fig. 4d-f. (MP4 $2807 \mathrm{~kb}$ )

Additional file 4: Video 3. Effect of targeted CALI on lysosomal motility. HeLa cells expressing LAMP1-mCh and RNb-SNAPf were imaged using TIRFM and 561-nm laser illumination before (top) and after (bottom) CALI (3.02 $\mathrm{s}$ exposure to $488-\mathrm{nm}$ epifluorescence laser illumination). The video was acquired at $0.5 \mathrm{~Hz}$ and is shown at $3 \mathrm{fps}$. The clock is in min:s. Relates to Fig. 8. (MP4 $776 \mathrm{~kb})$

Additional file 5: Video $4 \mathrm{RNb}-\mathrm{FKBP}$ rapidly sequesters an ER integral membrane protein at the OMM. TIRFM images of HeLa cells expressing TOM70-GFP-FRB, RNb-FKBP and $\mathrm{mCh}$-Sec61 $\beta$ were treated with rapamycin $(100 \mathrm{nM}$, added at $60 \mathrm{~s})$. The ER membrane protein, $\mathrm{mCh}$-Sec61 $\beta$, is then rapidly sequestered at the OMM. The video was acquired at $0.5 \mathrm{~Hz}$ and shown at $33 \mathrm{fps}$. The clock is in min:s. Relates to Fig. 10c, d. (MP4 551 kb)
Additional file 6: Video 5. GNb-FKBP rapidly sequesters endogenously tagged GFP-IP $R 1$ at the OMM. TIRFM images show HeLa cells with endogenously GFP-tagged $\mathrm{IP}_{3} \mathrm{R} 1$ and transiently expressing TOM70-mChFRB and GNb-FKBP, and then treated with rapamycin (100 nM, added at 60 s). GFP-IP $R 1$ is rapidly sequestered at the OMM. The video was acquired at $0.5 \mathrm{~Hz}$ and is shown at $33 \mathrm{fps}$. The clock is in min:s. Relates to Fig. $10 \mathrm{f}$ and g. (MP4 $2601 \mathrm{~kb}$ )

Additional file 7: Video 6. GNb-FKBP rapidly sequesters GFP-CaM at the OMM. Epifluorescence microscopy images show HeLa cells transiently expressing GFP-CaM, GNb-FKBP and TOM2O-mCh-FRB, and then treated with rapamycin (100 $\mathrm{nM}$, added at $30 \mathrm{~s}$ ). GFP-CaM is rapidly sequestered at the OMM. The video was acquired at $0.5 \mathrm{~Hz}$ and is shown at $9 \mathrm{fps}$. The clock is in min:s. Relates to Fig. 10h. (MP4 $362 \mathrm{~kb}$ )

Additional file 8: Video 7. RNb-FKBP recruits a PM protein to the OMM in response to rapamycin. TIRFM images of HeLa cells expressing TOM70GFP-FRB, RNb-FKBP and the PM protein, $\beta_{2} A R-m C h$, and then exposed to rapamycin ( $100 \mathrm{nM}$, added at $60 \mathrm{~s})$. There is a rapid translocation of $\beta_{2} \mathrm{AR}-$ $\mathrm{mCh}$ to the OMM. The video was acquired at $0.5 \mathrm{~Hz}$ and is shown at 33 fps. The clock is in min:s. Relates to Fig. 12b-e. (MP4 $2141 \mathrm{~kb})$

Additional file 9: Video 8. Crosslinking GNb-FKBP and RNb-FRB with rapamycin recruits $m C h-S e c 61 \beta$ to TOM20-GFP in the OMM. HeLa cells expressing GNb-FKBP, RNb-FRB, mCh-Sec61 $\beta$ and TOM20-GFP were stimulated with rapamycin ( $100 \mathrm{nM}$, added at $100 \mathrm{~s})$. The TIRFM images show rapid recruitment of $\mathrm{mCh}-\mathrm{Sec} 61 \beta$ to the OMM. The video was acquired at $0.2 \mathrm{~Hz}$ and is shown at $8 \mathrm{fps}$. The clock is in min:s. Relates to Fig. 16. (MP4 657 kb)

\section{Abbreviations}

$\left[\mathrm{Ca}^{2+}\right]_{c}$ : Cytosolic free $\mathrm{Ca}^{2+}$ concentration; BFP: Blue fluorescent protein; CALI: Chromophore-assisted light inactivation; CaM: Calmodulin; CFP: Cyan fluorescent protein; ER: Endoplasmic reticulum; FKBP: FK506-binding protein; FP: Fluorescent protein; FRB: FKBP-rapamycin-binding domain; GFP: Green fluorescent protein; GNb: GFP-binding nanobody; HBS: HEPES-buffered saline; $I_{3} R$ : Inositol 1,4,5-trisphosphate receptor; LAMP1: Lysosomal membrane protein 1; mCherry: Monomeric Cherry; MCS: Membrane contact site; MHBS: Modified HBS; MP: Multimerizing protein; mRFP: Monomeric red fluorescent protein; OMM: Outer mitochondrial membrane; PM: Plasma membrane; RFP: Red fluorescent protein; RNb: RFP-binding nanobody; ROI: Region of interest; SOCE: Store-operated $\mathrm{Ca}^{2+}$ entry; TIRFM: Total internal reflection fluorescence microscopy; YFP: Yellow fluorescent protein

\section{Acknowledgements}

Not applicable.

\section{Funding}

This work was supported by the Biotechnology and Biological Sciences Research Council UK (grant number BB/P005330/1) and a Wellcome Trust Senior Investigator Award (grant number 101844).

\section{Availability of data and materials}

All plasmids and data generated or analysed during this study are included in this published article and its supplementary information files. Plasmids are available from the corresponding authors on request and from Addgene.

\section{Authors' contributions}

DLP and CWT conceived the work. DLP conducted all the experiments and analysis. DLP and CWT interpreted the data and wrote the manuscript. DLP and CWT read and approved the final manuscript.

\section{Ethics approval and consent to participate}

Not applicable

\section{Competing interests}

The authors declare that they have no competing interests.

\section{Publisher's Note}

Springer Nature remains neutral with regard to jurisdictional claims in published maps and institutional affiliations. 
Received: 6 February 2019 Accepted: 2 May 2019 Published online: 23 May 2019

\section{References}

1. Clift D, McEwan WA, Labzin LI, Konieczny V, Mogessie B, James LC, et al. A method for the acute and rapid degradation of endogenous proteins. Cell. 2018;171:1692-706 e18.

2. Helma J, Cardoso MC, Muyldermans S, Leonhardt H. Nanobodies and recombinant binders in cell biology. J Cell Biol. 2015;209:633-44.

3. Shaner NC, Steinbach PA, Tsien RY. A guide to choosing fluorescent proteins. Nat Methods. 2005;2:905-9.

4. Rodriguez EA, Campbell RE, Lin JY, Lin MZ, Miyawaki A, Palmer AE, et al. The growing and glowing toolbox of fluorescent and photoactive proteins. Trends Biochem Sci. 2017;42:111-29.

5. Leonetti MD, Sekine S, Kamiyama D, Weissman JS, Huang B. A scalable strategy for high-throughput GFP tagging of endogenous human proteins. Proc Natl Acad Sci U S A. 2016;113:E3501-8.

6. Stewart-Ornstein J, Lahav G. Dynamics of CDKN1A in single cells defined by an endogenous fluorescent tagging toolkit. Cell Rep. 2016;14:1800-11.

7. Thillaiappan NB, Chavda AP, Tovey SC, Prole DL, Taylor CW. Ca ${ }^{2+}$ signals initiate at immobile $\mathrm{IP}_{3}$ receptors adjacent to ER-plasma membrane junctions. Nat Commun. 2017:8:1505.

8. Zhang J. The colorful journey of green fluorescent protein. ACS Chem Biol. 2009;4:85-8.

9. Stadler C, Rexhepaj E, Singan VR, Murphy RF, Pepperkok R, Uhlen M, et al. Immunofluorescence and fluorescent-protein tagging show high correlation for protein localization in mammalian cells. Nat Methods. 2013;10:315-23.

10. Hein MY, Hubner NC, Poser I, Cox J, Nagaraj N, Toyoda Y, et al. A human interactome in three quantitative dimensions organized by stoichiometries and abundances. Cell. 2015;163:712-23.

11. Nagarkar-Jaiswal S, Lee PT, Campbell ME, Chen K, Anguiano-Zarate S, Gutierrez MC, et al. A library of MiMICs allows tagging of genes and reversible, spatial and temporal knockdown of proteins in Drosophila. eLife. 2015;4:e05338.

12. Huh WK, Falvo JV, Gerke LC, Carroll AS, Howson RW, Weissman JS, et al. Global analysis of protein localization in budding yeast. Nature. 2003; 425:686-91.

13. Hayashi A, Ding DQ, Tsutsumi C, Chikashige $Y$, Masuda $H$, Haraguchi T, et al. Localization of gene products using a chromosomally tagged GFP-fusion library in the fission yeast Schizosaccharomyces pombe. Genes Cells. 2009;14:217-25.

14. Yofe I, Weill U, Meurer M, Chuartzman S, Zalckvar E, Goldman O, et al. One library to make them all: streamlining the creation of yeast libraries via a SWAp-tag strategy. Nat Methods. 2016;13:371-8.

15. Koroleva OA, Tomlinson ML, Leader D, Shaw P, Doonan JH. Highthroughput protein localization in Arabidopsis using Agrobacteriummediated transient expression of GFP-ORF fusions. Plant J. 2005:41:162-74

16. Tian GW, Mohanty A, Chary SN, Li S, Paap B, Drakakaki G, et al. Highthroughput fluorescent tagging of full-length Arabidopsis gene products in planta. Plant Physiol. 2004;135:25-38.

17. Kitagawa M, Ara T, Arifuzzaman M, loka-Nakamichi T, Inamoto E, Toyonaga $\mathrm{H}$, et al. Complete set of ORF clones of Escherichia coli ASKA library (a complete set of E. coli K-12 ORF archive): unique resources for biological research. DNA Res. 2005;12:291-9.

18. Eason MG, Damry AM, Chica RA. Structure-guided rational design of red fluorescent proteins: towards designer genetically-encoded fluorophores. Curr Opin Struct Biol. 2017;45:91-9.

19. Harikumar A, Edupuganti RR, Sorek M, Azad GK, Markoulaki S, Sehnalova P, et al. An endogenously tagged fluorescent fusion protein library in mouse embryonic stem cells. Stem Cell Rep. 2017;9:1304-14.

20. Pollithy A, Romer T, Lang C, Muller FD, Helma J, Leonhardt H, et al. Magnetosome expression of functional camelid antibody fragments (nanobodies) in Magnetospirillum gryphiswaldense. Appl Environ Microbiol. 2011;77:6165-71

21. Fridy PC, Li Y, Keegan S, Thompson MK, Nudelman I, Scheid JF, et al. A robust pipeline for rapid production of versatile nanobody repertoires. Nat Methods. 2014;11:1253-60.

22. Rothbauer U, Zolghadr K, Muyldermans S, Schepers A, Cardoso MC, Leonhardt $\mathrm{H}$. A versatile nanotrap for biochemical and functional studies with fluorescent fusion proteins. Mol Cell Proteomics. 2008;7:282-9.
23. Kanner SA, Morgenstern T, Colecraft HM. Sculpting ion channel functional expression with engineered ubiquitin ligases. eLife. 2017;6:e29744.

24. Caussinus E, Kanca O, Affolter M. Fluorescent fusion protein knockout mediated by anti-GFP nanobody. Nat Struct Mol Biol. 2011;19:117-21.

25. Borg S, Popp F, Hofmann J, Leonhardt H, Rothbauer U, Schuler D. An intracellular nanotrap redirects proteins and organelles in live bacteria. MBio. 2015;6:e02117.

26. Liu TK, Hsieh PY, Zhuang YD, Hsia CY, Huang CL, Lai HP, et al. A rapid SNAPtag fluorogenic probe based on an environment-sensitive fluorophore for no-wash live cell imaging. ACS Chem Biol. 2014;9:2359-65.

27. Filadi R, Pozzan T. Generation and functions of second messengers microdomains. Cell Calcium. 2015;58:405-14.

28. Ludwig FT, Schwab A, Stock C. The $\mathrm{Na}^{+} / \mathrm{H}^{+}$-exchanger (NHE1) generates pH nanodomains at focal adhesions. J Cell Physiol. 2012;228:1351-8.

29. Schlattner U, Klaus A, Ramirez Rios S, Guzun R, Kay L, Tokarska-Schlattner M. Cellular compartmentation of energy metabolism: creatine kinase microcompartments and recruitment of B-type creatine kinase to specific subcellular sites. Amino Acids. 2016;48:1751-74.

30. Zhao Y, Araki S, Wu J, Teramoto T, Chang YF, Nakano M, et al. An expanded palette of genetically encoded $\mathrm{Ca}^{2+}$ indicators. Science. 2011;333:1888-91.

31. Sankaranarayanan S, De Angelis D, Rothman JE, Ryan TA. The use of pHluorins for optical measurements of presynaptic activity. Biophys J. 2000;79:2199-208.

32. Shen $\mathrm{Y}$, Rosendale M, Campbell RE, Perrais D. pHuji, a pH-sensitive red fluorescent protein for imaging of exo- and endocytosis. J Cell Biol. 2014;207:419-32.

33. Tantama M, Martinez-Francois JR, Mongeon R, Yellen G. Imaging energy status in live cells with a fluorescent biosensor of the intracellular ATP-toADP ratio. Nat Commun. 2013;4:2550.

34. Atakpa P, Thillaiappan NB, Mataragka S, Prole DL, Taylor CW. IP 3 receptors preferentially associate with ER-lysosome contact sites and selectively deliver $\mathrm{Ca}^{2+}$ to lysosomes. Cell Rep. 2018;25:3180-93.

35. Mammucari C, Raffaello A, Vecellio Reane D, Gherardi G, De Mario A, Rizzuto R. Mitochondrial calcium uptake in organ physiology: from molecular mechanism to animal models. Pflugers Arch. 2018;470:1165-79.

36. Wang X, Schwarz TL. The mechanism of $\mathrm{Ca}^{2+}$-dependent regulation of kinesin-mediated mitochondrial motility. Cell. 2009;136:163-74.

37. Hajnóczky G, Robb-Gaspers LD, Seitz MB, Thomas AP. Decoding cytosolic calcium oscillations in the mitochondria. Cell. 1995;82:415-24.

38. Giacomello M, Drago I, Bortolozzi M, Scorzeto M, Gianelle A, Pizzo P, et al $\mathrm{Ca}^{2+}$ hot spots on the mitochondrial surface are generated by $\mathrm{Ca}^{2+}$ mobilization from stores, but not by activation of store-operated $\mathrm{Ca}^{2+}$ channels. Mol Cell. 2010;38:280-90.

39. Cole NB. Site-specific protein labeling with SNAP-tags. Curr Prot Prot Sci. 2013;73:30.1.1-30.1.16

40. Ries J, Kaplan C, Platonova E, Eghlidi H, Ewers H. A simple, versatile method for GFP-based super-resolution microscopy via nanobodies. Nat Methods. 2012;9:582-4.

41. Bodor DL, Rodriguez MG, Moreno N, Jansen LE. Analysis of protein turnover by quantitative SNAP-based pulse-chase imaging. Curr Prot Cell Biol. 2012; 55:8.8.1-8.8.34.

42. Sano Y, Watanabe W, Matsunaga S. Chromophore-assisted laser inactivation - towards a spatiotemporal-functional analysis of proteins, and the ablation of chromatin, organelle and cell function. J Cell Sci. 2014;127:1621-9.

43. Bonifacino JS, Neefjes J. Moving and positioning the endolysosomal system. Curr Opin Cell Biol. 2017:47:1-8.

44. Lee S, Park H, Kyung T, Kim NY, Kim S, Kim J, et al. Reversible protein inactivation by optogenetic trapping in cells. Nat Methods. 2014;11:633-6.

45. Robinson MS, Sahlender DA, Foster SD. Rapid inactivation of proteins by rapamycin-induced rerouting to mitochondria. Dev Cell. 2010;18:324-31.

46. Wang $H$, Vilela M, Winkler A, Tarnawski M, Schlichting I, Yumerefendi $H$, et al. LOVTRAP: an optogenetic system for photoinduced protein dissociation. Nat Methods. 2016;13:755-8.

47. Csordas G, Weaver D, Hajnoczky G. Endoplasmic reticular-mitochondrial contactology: structure and signaling functions. Trends Cell Biol. 2018;28:523-40.

48. Csordas G, Varnai P, Golenar T, Roy S, Purkins G, Schneider TG, et al. Imaging interorganelle contacts and local calcium dynamics at the ER-mitochondrial interface. Mol Cell. 2010;39:121-32.

49. Tepikin AV. Mitochondrial junctions with cellular organelles: $\mathrm{Ca}^{2+}$ signalling perspective. Pflugers Arch. 2018;470:1181-92.

50. Kennedy HJ, Pouli AE, Ainscow EK, Jouaville LS, Rizzuto R, Rutter GA. Glucose generates sub-plasma membrane ATP microdomains in single islet beta-cells. Potential role for strategically located mitochondria. J Biol Chem. 1999;274:13281-91. 
51. Quintana A, Pasche $M$, Junker C, Al-Ansary D, Rieger $H$, Kummerow C, et al. Calcium microdomains at the immunological synapse: how ORAl channels, mitochondria and calcium pumps generate local calcium signals for efficient T-cell activation. EMBO J. 2011;30:3895-912.

52. Frieden M, Arnaudeau S, Castelbou C, Demaurex N. Subplasmalemmal mitochondria modulate the activity of plasma membrane $\mathrm{Ca}^{2+}$-ATPases. J Biol Chem. 2005;280:43198-208.

53. Balla T. $\mathrm{Ca}^{2+}$ and lipid signals hold hands at endoplasmic reticulum-plasma membrane contact sites. J Physiol. 2017;596:2709-16.

54. Prakriya M, Lewis RS. Store-operated calcium channels. Physiol Rev. 2015:95:1383-436

55. Chang CL, Hsieh TS, Yang TT, Rothberg KG, Azizoglu DB, Volk E, et al. Feedback regulation of receptor-induced $\mathrm{Ca}^{2+}$ signaling mediated by E-Syt1 and Nir2 at endoplasmic reticulum-plasma membrane junctions. Cell Rep. 2013;5:813-25.

56. Simmen T, Tagaya M. Organelle communication at membrane contact sites (MCS): from curiosity to center stage in cell biology and biomedical research. Adv Exp Med Biol. 2017;997:1-12.

57. Wong YC, Ysselstein D, Krainc D. Mitochondria-lysosome contacts regulate mitochondrial fission via RAB7 GTP hydrolysis. Nature. 2017;554:382-6.

58. Torres S, Balboa E, Zanlungo S, Enrich C, Garcia-Ruiz C, Fernandez-Checa JC. Lysosomal and mitochondrial liaisons in Niemann-Pick disease. Front Physiol. 2017;8:982.

59. Wu J, Prole DL, Shen Y, Lin Z, Gnanasekaran A, Liu Y, et al. Red fluorescent genetically encoded $\mathrm{Ca}^{2+}$ indicators for use in mitochondria and endoplasmic reticulum. Biochem J. 2014:464:13-22.

60. Suzuki J, Kanemaru K, Ishii K, Ohkura M, Okubo Y, lino M. Imaging intraorganellar $\mathrm{Ca}^{2+}$ at subcellular resolution using CEPIA. Nat Commun. 2014:5:4153.

61. Suzuki J, Kanemaru K, lino M. Genetically encoded fluorescent indicators for organellar calcium imaging. Biophys J. 2016;111:1119-31.

62. Hirabayashi Y, Kwon SK, Paek H, Pernice WM, Paul MA, Lee J, et al. ERmitochondria tethering by PDZD8 regulates $\mathrm{Ca}^{2+}$ dynamics in mammalian neurons. Science. 2017;358:623-30.

63. Konieczny V, Tovey SC, Mataragka S, Prole DL, Taylor CW. Cyclic AMP recruits a discrete intracellular $\mathrm{Ca}^{2+}$ store by unmasking hypersensitive $\mathbb{P}_{3}$ receptors. Cell Rep. 2017;18:711-22.

64. Rodriguez-Prados M, Rojo-Ruiz J, Aulestia FJ, Garcia-Sancho J, Alonso MT. A new low- $\mathrm{Ca}^{2+}$ affinity GAP indicator to monitor high $\mathrm{Ca}^{2+}$ in organelles by luminescence. Cell Calcium. 2015;58:558-64.

65. Konieczny $\mathrm{V}$, Keebler MV, Taylor CW. Spatial organization of intracellular $\mathrm{Ca}^{2+}$ signals. Semin Cell Dev Biol. 2012;23:172-80.

66. Langeberg LK, Scott JD. Signalling scaffolds and local organization of cellular behaviour. Nat Rev Mol Cell Biol. 2015;16:232-44.

67. Ariotti N, Rae J, Giles N, Martel N, Sierecki E, Gambin Y, et al. Ultrastructural localisation of protein interactions using conditionally stable nanobodies. PLoS Biol. 2018;16:e2005473.

68. Rost BR, Schneider-Warme F, Schmitz D, Hegemann P. Optogenetic tools for subcellular applications in neuroscience. Neuron. 2017;96:572-603.

69. Ruggiu AA, Bannwarth M, Johnsson K. Fura-2FF-based calcium indicator for protein labeling. Org Biomol Chem. 2010;8:3398-401.

70. Kamiya M, Johnsson K. Localizable and highly sensitive calcium indicator based on a BODIPY fluorophore. Anal Chem. 2010;82:6472-9.

71. Bannwarth M, Correa IR, Sztretye M, Pouvreau S, Fellay C, Aebischer A, et al. Indo-1 derivatives for local calcium sensing. ACS Chem Biol. 2009;4:179-90.

72. Wang C, Song X, Xiao Y. SNAP-tag-based subcellular protein labeling and fluorescent imaging with naphthalimides. ChemBioChem. 2017;18:1762-9.

73. Abo M, Minakami R, Miyano K, Kamiya M, Nagano T, Urano Y, et al. Visualization of phagosomal hydrogen peroxide production by a novel fluorescent probe that is localized via SNAP-tag labeling. Anal Chem. 2014;86:5983-90.

74. Zimmermann M, Cal R, Janett E, Hoffmann V, Bochet CG, Constable E, et al. Cell-permeant and photocleavable chemical inducer of dimerization. Angew Chem Int Ed Engl. 2014;53:4717-20.

75. Feng S, Laketa V, Stein F, Rutkowska A, MacNamara A, Depner S, et al. A rapidly reversible chemical dimerizer system to study lipid signaling in living cells. Angew Chem Int Ed Engl. 2014;53:6720-3.

76. Putyrski M, Schultz C. Protein translocation as a tool: the current rapamycin story. FEBS Lett. 2012;586:2097-105.

77. Marschall AL, Dubel S, Boldicke T. Specific in vivo knockdown of protein function by intrabodies. MAbs. 2015;7:1010-35.

78. Michelangeli F, Ogunbayo OA, Wootton LL. A plethora of interacting organellar $\mathrm{Ca}^{2+}$ stores. Curr Opin Cell Biol. 2005;17:135-40.
79. Wong AK, Capitanio P, Lissandron V, Bortolozzi M, Pozzan T, Pizzo P. Heterogeneity of $\mathrm{Ca}^{2+}$ handling among and within Golgi compartments. J Mol Cell Biol. 2013;5:266-76.

80. Crevenna AH, Blank B, Maiser A, Emin D, Prescher J, Beck G, et al. Secretory cargo sorting by $\mathrm{Ca}^{2+}$-dependent $\mathrm{Cab45}$ oligomerization at the trans-Golgi network. J Cell Biol. 2016;213:305-14

81. Appenzeller C, Andersson H, Kappeler F, Hauri HP. The lectin ERGIC-53 is a cargo transport receptor for glycoproteins. Nat Cell Biol. 1999;1:330-4.

82. Mitchell KJ, Pinton P, Varadi A, Tacchetti C, Ainscow EK, Pozzan T, et al. Dense core secretory vesicles revealed as a dynamic $\mathrm{Ca}^{2+}$ store in neuroendocrine cells with a vesicle-associated membrane protein aequorin indicator. J Cell Biol. 2001;155:41-51.

83. Mundorf ML, Troyer KP, Hochstetler SE, Near JA, Wightman RM. Vesicular $\mathrm{Ca}^{2+}$ participates in the catalysis of exocytosis. J Biol Chem. 2000;275:9136-42.

84. Harmansa S, Affolter M. Protein binders and their applications in developmental biology. Development. 2018;145:dev148874.

85. Tiede C, Bedford R, Heseltine SJ, Smith G, Wijetunga I, Ross R, et al. Affimer proteins are versatile and renewable affinity reagents. eLife. 2017;6:e24903.

86. Sha F, Salzman G, Gupta A, Koide S. Monobodies and other synthetic binding proteins for expanding protein science. Protein Sci. 2017;26:910-24.

87. Wozniak MJ, Bola B, Brownhill K, Yang YC, Levakova V, Allan VJ. Role of kinesin-1 and cytoplasmic dynein in endoplasmic reticulum movement in VERO cells. J Cell Sci. 2009;122:1979-89.

88. Lopez Sanjurjo Cl, Tovey SC, Prole DL, Taylor CW. Lysosomes shape Ins $(1,4,5) \mathrm{P}_{3}$-evoked $\mathrm{Ca}^{2+}$ signals by selectively sequestering $\mathrm{Ca}^{2+}$ released from the endoplasmic reticulum. J Cell Sci. 2013;126:289-300.

89. Brailoiu E, Churamani D, Cai X, Schrlau MG, Brailoiu GC, Gao X, et al. Essential requirement for two-pore channel 1 in NAADP-mediated calcium signaling. J Cell Biol. 2009;186:201-19.

90. Kanda T, Sullivan KF, Wahl GM. Histone-GFP fusion protein enables sensitive analysis of chromosome dynamics in living mammalian cells. Curr Biol. 1998;8:377-85.

91. English AR, Voeltz GK. Rab10 GTPase regulates ER dynamics and morphology. Nat Cell Biol. 2013;15:169-78.

92. Cheeseman LP, Harry EF, MCAinsh AD, Prior IA, Royle SJ. Specific removal of TACC3-ch-TOG-clathrin at metaphase deregulates kinetochore fiber tension. J Cell Sci. 2013;126:2102-13.

93. Goedhart J, von Stetten D, Noirclerc-Savoye M, Lelimousin M, Joosen L, Hink MA, et al. Structure-guided evolution of cyan fluorescent proteins towards a quantum yield of 93\%. Nat Commun. 2012;3:751.

94. Violin JD, Ren XR, Lefkowitz RJ. G-protein-coupled receptor kinase specificity for $\beta$-arrestin recruitment to the $\beta_{2}$-adrenergic receptor revealed by fluorescence resonance energy transfer. J Biol Chem. 2006;281:20577-88.

95. Schindelin J, Arganda-Carreras I, Frise E, Kaynig V, Longair M, Pietzsch T, et al. Fiji: an open-source platform for biological-image analysis. Nat Methods. 2012;9:676-82.

96. Jaqaman K, Loerke D, Mettlen M, Kuwata H, Grinstein S, Schmid SL, et al. Robust single-particle tracking in live-cell time-lapse sequences. Nat Methods. 2008:5:695-702.

97. Bolte S, Cordelieres FP. A guided tour into subcellular colocalization analysis in light microscopy. J Microsc. 2006;224:213-32.

Ready to submit your research? Choose BMC and benefit from

- fast, convenient online submission

- thorough peer review by experienced researchers in your field

- rapid publication on acceptance

- support for research data, including large and complex data types

- gold Open Access which fosters wider collaboration and increased citations

- maximum visibility for your research: over $100 \mathrm{M}$ website views per year

At BMC, research is always in progress.

Learn more biomedcentral.com/submissions 